\title{
The Durability of High-Strength Concrete Containing Waste Tire Steel Fiber and Coal Fly Ash
}

\author{
Babar Ali ${ }^{1},{ }^{1}$ Erol Yilmaz $\left({ }^{2},{ }^{2}\right.$ Ahmad Raza Tahir, ${ }^{1}$ Fehmi Gamaoun, ${ }^{3,4}$ \\ Mohamed Hechmi El Ouni, ${ }^{5,6}$ and Syed Muhammad Murtaza Rizvi ${ }^{1}$ \\ ${ }^{1}$ Department of Civil Engineering (CVE), COMSATS University Islamabad (CUI)-Sahiwal Campus, Sahiwal 57000, Pakistan \\ ${ }^{2}$ Department of Civil Engineering, Recep Tayyip Erdoğan University, Rize, Turkey \\ ${ }^{3}$ Department of Mechanical Engineering, College of Engineering, King Khalid University, Abha 61421, Saudi Arabia \\ ${ }^{4}$ Laboratory of Mechanics of Sousse, National Engineering School of Sousse, University of Sousse, Sousse 4054, Tunisia \\ ${ }^{5}$ Department of Civil Engineering, College of Engineering, King Khalid University, P.O. Box 394, Abha 61411, Saudi Arabia \\ ${ }^{6}$ Applied Mechanics and Systems Research Laboratory, Tunisia Polytechnic School, University of Carthage, La Marsa, \\ Tunis 2078, Tunisia
}

Correspondence should be addressed to Babar Ali; babar.ali@cuisahiwal.edu.pk

Received 28 July 2021; Accepted 27 October 2021; Published 12 November 2021

Academic Editor: Akbar Heidarzadeh

Copyright (c) 2021 Babar Ali et al. This is an open access article distributed under the Creative Commons Attribution License, which permits unrestricted use, distribution, and reproduction in any medium, provided the original work is properly cited.

The demands for high-strength concrete (HSC) have been increasing rapidly in the construction industry due to the requirements of thin and durable structural elements. HSC is highly brittle. Therefore, to augment its ductility behavior, expensive fibers are used. These negative drawbacks of HSC can be controlled by incorporating waste materials into its manufacturing instead of conventional ones. Therefore, this study assessed the performance of HSC produced with different quantities of waste tire steel fiber (WSF) and fly ash (FA). WSF was used at two doses, namely, $0.5 \%$ and $1 \%$, by volume in HSC, with low-to-medium volumes of FA, that is, $10 \%-35 \%$. The studied durability parameters included rapid chloride permeability (RCP) and chloride penetration depth (CPD) by immersion method (28 and 120 days) and acid attack resistance (AAR) (28 and 120 days). Various basic mechanical properties of HSC were also analyzed, such as compressive strength $\left(f_{\mathrm{CM}}\right)$, modulus of elasticity $\left(E_{\mathrm{CM}}\right)$, splittingtensile strength $\left(f_{\mathrm{CTM}}\right)$, and modulus of rupture $\left(f_{\mathrm{CRM}}\right)$. The results revealed that the damaging effect of WSF on the RCP resistance of HSC is probably due to the high conductivity of steel fibers. However, test results of CPD showed that WSF produced insignificant changes in chloride permeability of HSC. Furthermore, when made with FA, WSF-reinforced HSC yielded very low chloride permeability. Both WSF and FA contributed to the improvement in the AAR of HSC. WSF was highly useful to tensile properties while it showed minor effects on compressive properties $\left(f_{\mathrm{CM}}\right.$ and $\left.E_{\mathrm{CM}}\right)$. Optimum ductility and durability can be achieved with HSC incorporating 1\% WSF and 10\%-15\% FA.

\section{Introduction}

The impacts of cement concrete manufacturing and its uses are quite complex to comprehend. Some impacts are positive, and others are negative, depending on the situation. Portland cement is the vital ingredient of concrete that has various environmental, economic, and social impacts. The impacts of cement also contribute to those of the concrete. The cement industry alone releases about $7 \%$ of the total greenhouse emissions produced all over the world [1]. Rapid growth in urban populations and the requirement of modern infrastructure have increased the demand for cement, which consequently reflects badly on the quality of the environment and social life. About 0.7-1 kilogram of global warming gases is produced due to 1-kilogram production of Portland cement, depending on the type of energy source and technology employed to manufacture cement [2]. While the other ingredients of concrete such as sand and gravels have a small $\mathrm{CO}_{2}$ footprint, their cost and $\mathrm{CO}_{2}$ footprint largely depend on their transportation distances between the 
quarry and concrete batching plant. Therefore, about $85 \%$ of emissions of cement concrete are dependent on the binder constituent of concrete $[3,4]$. The most effective way to control the environmental impact of concrete is to minimize its cement consumption. This can be achieved by the utilization of industrial waste powders that possess pozzolanicity and hydraulicity. The substitution of a small and medium volume of cement with these waste powders can drastically reduce the $\mathrm{CO}_{2}$ footprint of concrete. However, the efficacy of potential cement substitution materials should be assessed properly in terms of their contribution towards durability and mechanical performance. The cost to strength $[5,6]$ or $\mathrm{CO}_{2}$ footprint to strength ratio analysis [7] should always be performed to judge the technical performance of cementitious materials.

Fly ash (FA) is a common waste mineral powder, which is a product of pulverized fuel ash burning for electric power generation. FA incorporation into cement concrete cannot only decrease the $\mathrm{CO}_{2}$ footprint of concrete, but it can also resolve waste disposal problems associated with high volumes of coal ashes. FA can help in gaining a circular economy in modern-day concrete manufacturing. Pakistan relies heavily on nonrenewable supplies of energy, such as coal-fed power plants. Therefore, abundant supplies of FA are available in this country. FA is rich in alumina-silica, and it has minor amounts of calcium and iron oxides. It qualifies as a potential cement replacement material [8]. The effects of FA on the properties of concrete have been studied properly. It helps in the slow consumption of residual portlandite $\mathrm{Ca}(\mathrm{OH})_{2}$ and positively affects the resistance of concrete against water absorption, chloride attack, and drying shrinkage [9-11]. Low levels of FA can cause minor improvements in the mechanical performance of concrete [12], but its high levels drastically reduce mechanical strength $[7,13]$. The degree of the effectiveness of FA depends on its fineness, chemical composition, and unburnt carbon content [14-17]. Generally, FA with high fineness and low carbon content is considered suitable for concrete applications.

Due to the increasing information gained related to material availability, design, and construction techniques, the practical scope of high-strength concrete (HSC) applications has been expanded dramatically. Rising inclination towards lightweight elements, large spans in buildings and bridges have increased the demands for HSC. However, there is a faction among designers unwilling to use HSC owing to its some drawbacks compared to conventional normal strength concrete (NSC) [18]. To begin with, HSC has a low $f_{\mathrm{CTM}}$ compared to its $f_{\mathrm{CM}}$. The increase in the strength class of concrete reduces the ratio between $f_{\text {CTM }}$ and $f_{\text {CM }}$ [19]. This means that the gain in $f_{\text {СTM }}$ achieved due to the low water-cement ratio is not proportional to the gain in

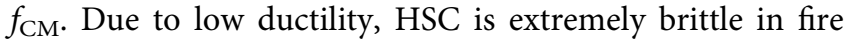
temperatures. Due to a dense microstructure, the fire resistance of HSC is incredibly lower than the NSC [20].

The brittleness issue of HSC can be addressed by using fibers. Various options for fiber reinforcements are available, such as steel, carbon, polypropylene, polyvinyl, and glass fibers [21-23]. The use of fibers substantially enhances the tensile and fracture toughness of HSC. The selection of fiber type varies depending upon the application of HSC. Fiber addition is highly useful in enhancing $f_{\mathrm{CTM}}$ and flexural strength $f_{\mathrm{CRM}}$ of HSC [22]. In short, fibers can overcome the inherent issue of brittleness associated with both plain HSC and NSC. Research has shown the negative effects of fiber addition on the economy and the environmental impact of concrete [24]. High transportation distances significantly increase the cost and $\mathrm{CO}_{2}$ footprint of fibers [24]. Their small doses can noticeably increase the cost and $\mathrm{CO}_{2}$ footprint of concrete. Fiber addition also requires technical supervision; it creates workability issues when used in HSC. Therefore, the use of additional measures and materials to control the quality of concrete can increase the final cost. Therefore, the selection of fiber type should be made based on a comprehensive cost to benefit ratio analysis.

The development of ductile, cheap, and environmentfriendly HSC is not possible without considering the less energy-intensive fibers compared to industrially manufactured fibers available at distant locations. Currently, researchers are investigating the potential of waste tire steel fibers (WSF) as the fiber reinforcement in cement concrete. Since WSF is composed of ultra-high-strength steel wires, which are designed for good fatigue resistance, it can become a potential fiber reinforcement material. WSF behaves similar to virgin steel fiber to a great extent, considering the properties of ultra-high performance concrete [25]. Considering the wider availability of old waste tires, WSF can become a local fiber-reinforcement material in all regions of the world, so high transportation costs can be avoided by adopting WSF instead of industrial fibers.

New steel fiber and WSF behave similarly as fiber reinforcement due to the same material. Small doses of WSF can be useful to $f_{\mathrm{CM}}$ of concrete, whereas using a large dose of WSF can lessen the $f_{\mathrm{CM}}$ of concrete [26]. A high dose of WSF increases the porosity of concrete due to workability issues that reflect badly in terms of compression stiffness of concrete [26]. WSF can postpone the collapse of concrete under compression; it can ensure ductile and slow cracking with a significant warning before collapse [27]. The effect of WSF on the properties of concrete significantly depends on the length, shape, texture, and residual rubber content of fiber [28]. The incorporation of $0.46 \%$ volume of irregularshaped WSF in concrete improved its $f_{\mathrm{CM}}$ by $25 \%$ [29]. At the same volume of $0.75 \%$ WSF and new steel fibers, $f_{\text {CTM }}$ of concrete increased by $28 \%$ and $26 \%$, respectively, whereas by the use of WSF carrying mixed filament lengths, $f_{\text {СтM }}$ of plain concrete was increased by about 50\% [30, 31]. Similar to compressive behavior, the postpeak flexure response of concrete depends on the type, dose, and the number of filaments per unit volume. $f_{\text {CRM }}$ of concrete significantly increases with the rise in WSF dosage [32, 33]. WSF provides a crack-arresting mechanism that helps in delaying the onset of rupture failure of concrete [31, 34-37].

The incorporation of FA and WSF into HSC can integrate the benefits of ductility, durability, and ecofriendliness. The simultaneous use of waste mineral admixtures and fibers proves beneficial in three different ways: (1) fine particles of mineral admixtures can improve the distribution of 
filaments throughout the matrix of concrete [38], [39]; (2) mineral admixtures increase the interface between filaments and binder matrix that improves the bond performance of fibers [40, 41]; and (3) some mineral admixtures reduce the water demand of concrete due to their slow hydration and filling action, hence reducing the requirement of water-reducing agents to maintain the workability of fiber-reinforced concretes [42-45]. Due to these benefits, fibers and mineral admixture addition show some synergistic results on the performance of concrete [9]. There are very few studies that investigate the combined behavior of FA and WSF. However, many studies are available related to the combined behavior of industrial fibers and waste mineral admixtures (i.e., FA, silica fume, slag, etc.) [46-48]. The combined behavior of WSF and mineral admixture was studied by Mastali and Dalvand [27]. They found that the combined addition of silica fume and WSF improves the overall toughness and strength of concrete.

Very little information is available on the durability behavior of HSC made with the combined incorporation of WSF and FA. Moreover, information on mechanical behavior is also deficient. Due to already explained environmental, economic, and ductility benefits, the combined effect of WSF and FA should be properly investigated on the properties of HSC. Therefore, this research aimed to evaluate the effects of different combinations of FA $(0,10,15,25$, and $35 \%)$ and WSF (0, 0.5 , and $1 \%)$ on the properties of HSC. The examined durability parameters involve RCP and CPD by immersion method (at 28 and 120 days) and AAR (at 28 and 120 days). Various basic mechanical properties of HSC were also studied experimentally, such as $f_{\mathrm{CM}}, f_{\mathrm{CTM}}, f_{\mathrm{CRM}}$, and $E_{\mathrm{CM}}$. The findings of this research fill an important research gap related to the durability of waste tire steel fiberreinforced concrete. Moreover, the combined effect of FA and WSF on both durability and mechanical properties of HSC has never been studied before.

\section{Materials and Methods}

\subsection{Constituent Materials}

2.1.1. Binding Materials. HSC mixes were prepared with 53grade cement, which was used as the major binder. It is qualified as "Type-I cement" per ASTM C150 [49]. FA containing a low percentage of lime was acquired from a local coal power plant. It was a by-product of bituminous coal. The generation of FA was estimated to be $10 \%$ of the annual cement production of Pakistan. The composition of the FA is Class F type, known for pozzolanicity potential but low hydraulicity. Important properties of FA and 53-grade cement are given in Table 1.

2.1.2. Aggregates. Quarry sand of "Lawrencepur" was used as fine aggregate to manufacture HSC. This sand is recommended for good-quality concrete production in Punjab, Pakistan. This coarse-grained sand has a good distribution of particle sizes and has a "fineness moduli" of 2.92. Crushed dolomite sandstone was used as coarse aggregate. This aggregate was derived from Kirana Hills of Sargodha, Punjab,
Pakistan. Engineering properties of fine and coarse aggregates are given in Table 2, which were important inputs in the mix design procedure of HSC. The diversity in particle sizes of both "quarry sand" and "crushed coarse aggregate" is shown in Figure 1. The maximum aggregate sizes for "fine" and "coarse" aggregates are 4.75 and $12.5 \mathrm{~mm}$, respectively.

2.1.3. WSF. WSF used in this research was derived from old waste tires of truck vehicles. The tire-bead wires, when removed from waste tires, contained residual rubber. Therefore, heat treatment was applied to remove the rubber particles from steel wires. Removing rubber particles is necessary to ensure a good bond between fibers and the matrix of the concrete. Moreover, rubber reduces $f_{\mathrm{CM}}$ of concrete owing to its low density [28]. Finally, clean steel wires were chopped into lengths of about $30 \mathrm{~mm}$. WSF consists of spun filaments as can be noticed in Figure 2. The diameter of each filament was about $1.2 \mathrm{~mm}$. WSF also contains microsteel wires that were twined around the main filament in the tire bead. These small wires may provide hybrid (mixed-length and mixed-diameter effects) of fibers on the properties of HSC.

2.1.4. Water-Reducing Agent and Water. The desired workability of an HSC mixture was achieved by using a commercial third-generation water-reducing agent "ViscoCrete 3110." It also helped in controlling the drop in workability due to the addition of WSF. Tap water from the concrete laboratory was used in the preparation and curing of HSC mixes. It has a $\mathrm{pH}$ of 7.9 and total dissolved solid content of $170 \mathrm{mg} / \mathrm{L}$.

\subsection{Design HSC Concrete Mixes with Different Combinations} of WSF and FA. In this research control or reference, HSC was designed for a cubical $f_{\mathrm{CM}}$ of $70 \mathrm{MPa}$. This strength class was achieved by employing a water-binder ratio of 0.30 . In order to achieve good workability (a slump value of $190-210 \mathrm{~mm}$ ), the "ViscoCrete 3110 " water-reducing agent was used at $0.75 \%$ by weight of binder in reference HSC. Details about the composition of a reference mix are given in Table 3. In HSC, FA was used at five different levels, $0 \%, 10 \%$, $15 \%, 25 \%$, and $35 \%$, by volumetric replacement of cement. Since FA is lighter than cement, the replacement of cement with FA should be done by volume. Then, with each incorporation level of FA, three different doses of WSF, $0 \%$, $0.5 \%$, and $1 \%$, by a volumetric fraction of concrete were used. Therefore, the experimental campaign studied a total of 15 concrete mixtures. Details of all 15 mixes are given in Table 3. It is worth mentioning here that plain HSC mixtures containing FA achieved the required range of workability at $0.75 \%$ dose of water-reducing agent, while all fiber-reinforced HSC mixes required a $1 \%$ dose of water-reducing agent to achieve desirable workability. The workability was because the use of WSF increased the stiffness of fresh concrete. Therefore, the loss in workability due to the fiber addition was compensated with a high dose of plasticizer. All plain mixtures (without fibers) (serial nos. 1, 4, 7, 10, 13) 
TABLE 1: Engineering characteristics of binders used in this study.

\begin{tabular}{lccccccccc}
\hline \multirow{2}{*}{ Binder } & \multicolumn{4}{c}{ Chemical properties } & \multicolumn{3}{c}{ Physical properties } \\
& $\mathrm{CaO}$ & $\mathrm{Al}_{2} \mathrm{O}_{3}$ & $\mathrm{SiO}_{2}$ & $\mathrm{Fe}_{2} \mathrm{O}_{3}$ & LOI & PSG & Density $\left(\mathrm{kg} / \mathrm{m}^{3}\right)$ & SSA $\left(\mathrm{m}^{2} / \mathrm{kg}\right)$ & Soundness $(\%)$ \\
\hline FA & 4.3 & 28.4 & 61.0 & 3.4 & 1.4 & 2.31 & 1128 & 345 & - \\
Cement & 64.2 & 6.7 & 23.9 & 4.3 & 4.7 & 3.12 & 1441 & 321 & 0.09 \\
\hline
\end{tabular}

LOI: loss on ignition; PSG: particle specific gravity; SSA: specific surface area.

TABLE 2: Engineering characteristics of aggregates used in this research.

\begin{tabular}{lcccr}
\hline \multirow{2}{*}{ Aggregate type } & \multicolumn{2}{c}{ Particle size (mm) } & WA (\%) & PSG \\
& Max & Min & FM \\
\hline Quarry sand (fine aggregate) & 4.75 & 0.075 & 0.76 & 2.66 \\
Crushed sandstone (coarse aggregate) & 12.5 & 2.36 & 0.79 & 2.92 \\
\hline
\end{tabular}

WA: water absorption at $24 \mathrm{hrs}$; PSG: particle specific gravity; FM: fineness modulus.

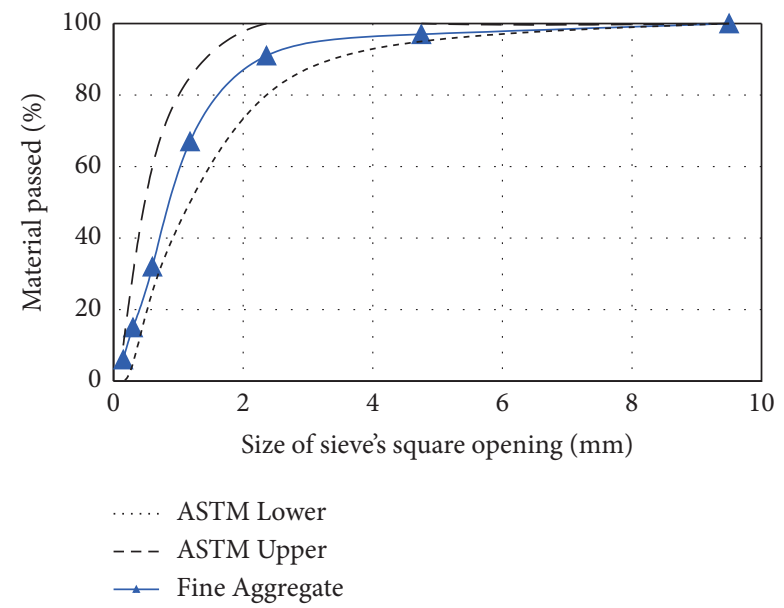

(a)

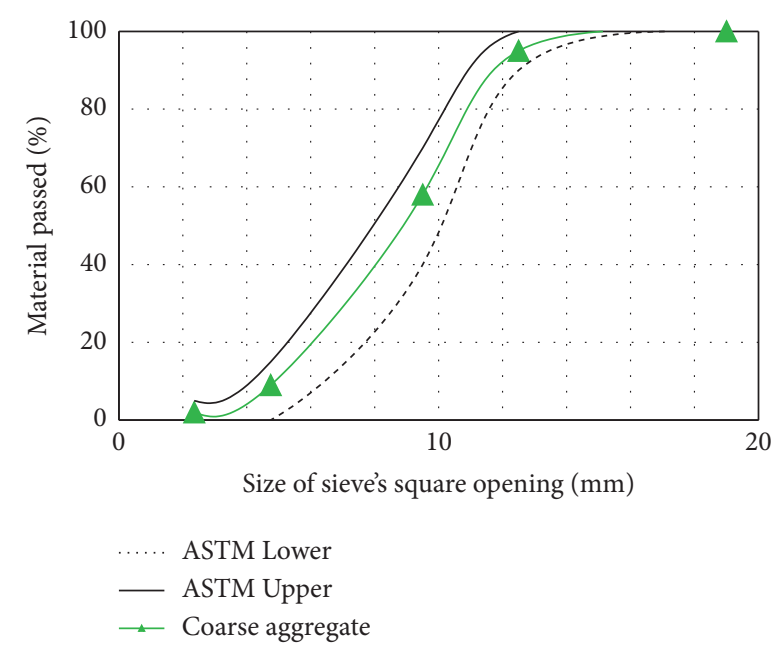

(b)

FIGURE 1: The aggregate size gradation curves of (a) quarry sand and (b) coarse aggregate following ASTM C33 [50].
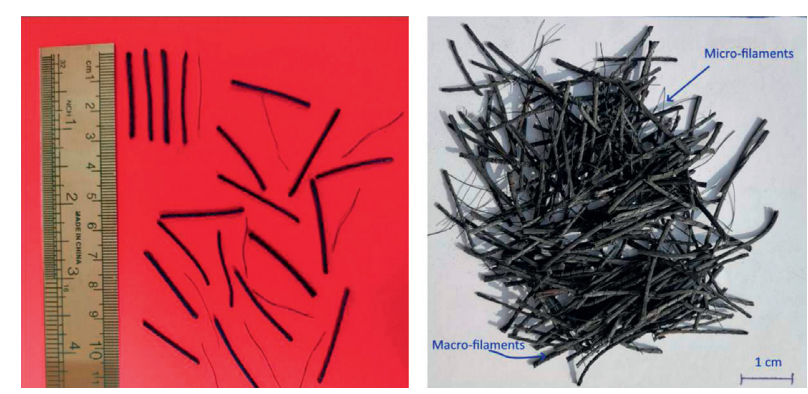

Figure 2: An overview of a random sample of WSF.

attained a slump value of $180-210 \mathrm{~mm}$, while WSF-reinforced mixes (serial nos. 2, 3, 5, 6, 8, 9, 11, 12, 14, and 15) attained slump values of $125-145 \mathrm{~mm}$.

2.3. Mixing Method. HSC mixes containing WSF (serial nos. 2, 3, 5, 6, 8, 9, 11, 12, 14, and 15) were mixed in four continuous stages: (1) in the first step, cement, FA, and aggregates were mixed in machine mixer for 2 mins at a speed of $40 \mathrm{rev} / \mathrm{min}$ (revolutions per minute); (2) in the second step, half the amount of water and water-reducing agents were added to mix and blend in machine mixer continued for $2 \mathrm{mins}$ at a speed of $40 \mathrm{revs} / \mathrm{min}$; (3) in the third step, the remaining quantities of water-reducing agent and water were added and mixed, and blending was done at high speed of $60 \mathrm{rev} / \mathrm{min}$ for $2 \mathrm{mins}$; and (4) in the 
TABLE 3: Information about the composition of concrete mixtures.

\begin{tabular}{lccccccccc}
\hline $\begin{array}{l}\text { Serial. } \\
\text { no. }\end{array}$ & Mix ID & $\begin{array}{c}\text { FA } \\
(\%)\end{array}$ & $\begin{array}{c}\text { WSF } \\
(\%)\end{array}$ & $\begin{array}{c}\text { Cement } \\
\left(\mathrm{kg} / \mathrm{m}^{3}\right)\end{array}$ & $\begin{array}{c}\text { FA } \\
\left(\mathrm{kg} / \mathrm{m}^{3}\right)\end{array}$ & $\begin{array}{c}\text { Fine aggregate } \\
\left(\mathrm{kg} / \mathrm{m}^{3}\right)\end{array}$ & $\begin{array}{c}\text { Coarse aggregate } \\
\left(\mathrm{kg} / \mathrm{m}^{3}\right)\end{array}$ & $\begin{array}{c}\text { WSF } \\
\left(\mathrm{kg} / \mathrm{m}^{3}\right)\end{array}$ & $\begin{array}{c}\text { Water } \\
\left(\mathrm{kg} / \mathrm{m}^{3}\right)\end{array}$ \\
\hline 1 & F0WF0 & & 0 & 500 & 0 & 865 & 904 & 0 & 150 \\
$(\%)$
\end{tabular}

fourth stage, measured quantities of WSF were charged into the mixer, and machine mixing was done for 4 mins at $80 \mathrm{revs} / \mathrm{min}$ to ensure proper dispersion of cement particles and fiber filaments. Plain mixes (serial nos. 1, 4, $7,10,13)$ were mixed in the first three stages which were used for the mixing of WSF-HSC mixes.

After completion of mixing, fresh concrete mixtures were tested for the slump, and mixes qualifying the workability requirements were proceeded for casting. During the casting stage, the machine mixer kept running at a low speed of $40 \mathrm{rev} / \mathrm{min}$. Casting was completed within $4-5 \mathrm{mins}$ of completion of the mixing stage.

2.4. Sample Details and Testing Methods. Six cubes of $100 \mathrm{~mm}$ dimensions were prepared for each mixture. The $f_{\mathrm{CM}}$ was determined at 28 and 120 days; three cubes of each mix were tested at one age. The standard of testing was followed as per ASTM C39 [51]. The testing setup is shown in Figure 3(a). Cylindrical samples of $100 \mathrm{~mm}$ diameter and $200 \mathrm{~mm}$ height were cast for $E_{\mathrm{CM}}$ testing, as shown in Figure 3(b). Three cylinders per mix were cast, of which were tested at 28 days and the remaining three 120 days. The standard of testing was adopted from ASTM C469 [52]. This test was performed to estimate the effect of WSF on the ductility of samples. For this purpose, cylindrical specimens of " $100 \mathrm{~mm}$ diameter and $200 \mathrm{~mm}$ " height were prepared. Three replica samples of each mix were tested at 28 days. The standard of testing was adopted from ASTM C496 [53]. The testing overview is shown in Figure 3(c). "Flexural strength" or "modulus of rupture $f_{\text {CRM }}$ " is a tensile property of concrete that is employed in the design equations of flexural elements, such as slabs and pavements. For each mix, three specimens having dimensions of $100 \mathrm{~mm} \times 100 \mathrm{~mm} \times 350 \mathrm{~mm}$ were tested for the calculation of $f_{\mathrm{CRM}} \cdot f_{\mathrm{CRM}}$ was determined under the thirdpoint loading method adopted from ASTM C1609 [54]. The test setup is shown in Figure 3(d).
The chloride durability is an important characteristic of concrete that tells about the life of a reinforced structural element. $R C P$ test was conducted on $100 \mathrm{~mm}$ diameter $\times 50 \mathrm{~mm}$ height disc specimens of each mix. The test method was adopted from ASTM C1202 [55]. RCP test was performed by maintaining a potential difference of 60 volts for the duration of $6 \mathrm{hrs}$. The overview of RCP testing is shown in Figure 4.

Chloride-ion penetration depth $(C P D)$ by immersion method was also measured to understand the effects of WSF and FA on the permeability of chloride ions in the absence of applied voltage. Since WSF addition highly increases the electrical conductivity of HSC [43], it becomes more convenient to adopt the natural process of measuring chloride penetrability of HSC rather than the $R C P$ test, to avoid wrong interpretation of $R C P$ test results of steel fiberreinforced concretes. For the immersion test method, six cylindrical specimens $(100 \mathrm{~mm}$ height $\times 100 \mathrm{~mm}$ diameter $)$ of each mix were cured in tap water for 28 days, and then airdried for 3 days at room temperature. These air-dried specimens were then soaked in a $10 \%$ solution of sodium chloride $(\mathrm{NaCl})$ salt. $C P D$ was then measured by spraying 0.1 normality solution of silver nitrate $\left(\mathrm{AgNO}_{3}\right)$ salt, on the split surfaces of $\mathrm{NaCl}$ conditioned samples after periods of 28 and 120 days. Three replica samples were tested at each age to determine the average $C P D$ value of each HSC mix.

Measuring the $A A R$ of HSC is very important, as there are some applications where concrete experiences harsh acidic environments, such as in components of sewerage networks. Method of $A A R$ testing was adopted from a previous study [9], where $A A R$ was measured by quantifying the differences between fresh samples and acid exposed samples. For $A A R$ testing, three replica specimens $(100 \mathrm{~mm}$ cubes) of each mix were cured in tap water for 28 days. These specimens were then air-dried at room temperature for 3 days. Then, the samples of all mixes were exposed to sulfuric acidic $\left(\mathrm{H}_{2} \mathrm{SO}_{4}\right)$ solution of $5 \%$ concentration. The change in 


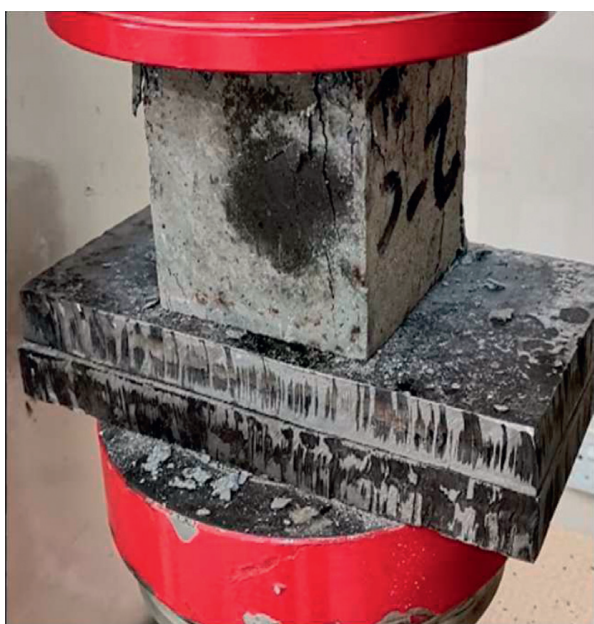

(a)

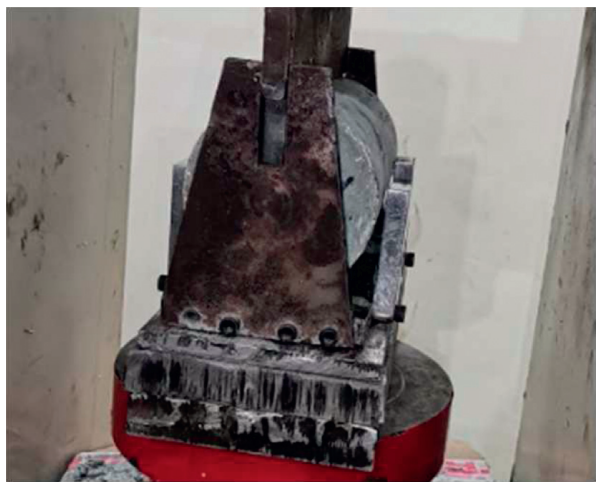

(c)

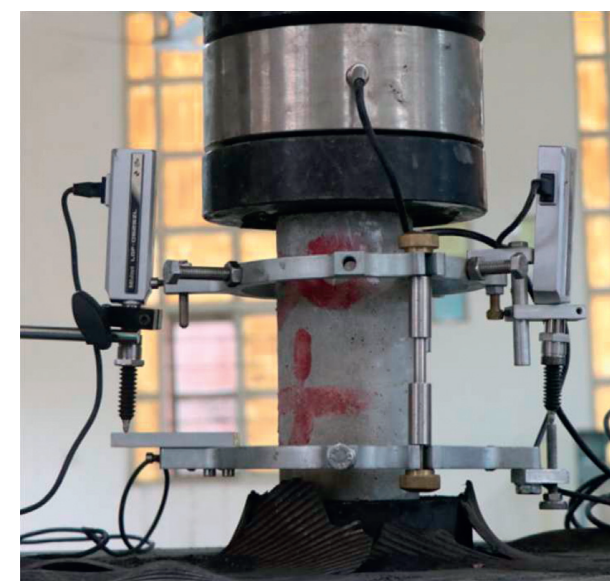

(b)

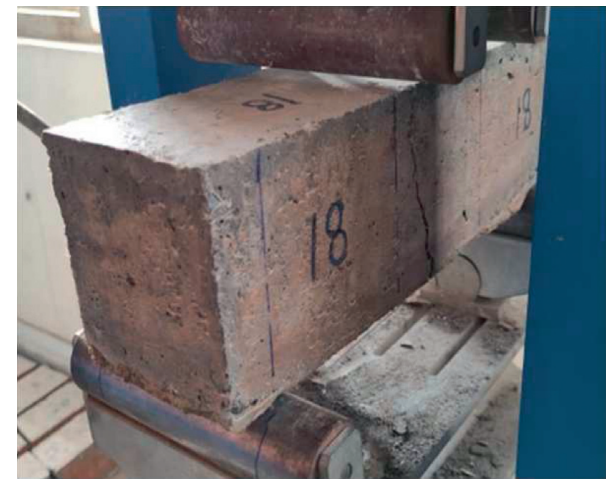

(d)

Figure 3: Overview of mechanical testing. (a) Compression test on $100 \mathrm{~mm}$ cubes. (b) Overview of axial testing for ECM determination. (c) Splitting-tensile test on " $100 \mathrm{~mm} \times 200 \mathrm{~mm}$ " cylindrical samples. (d) Overview of flexural testing on " $100 \mathrm{~mm} \times 100 \mathrm{~mm} \times 350 \mathrm{~mm}$ " prismatic samples.

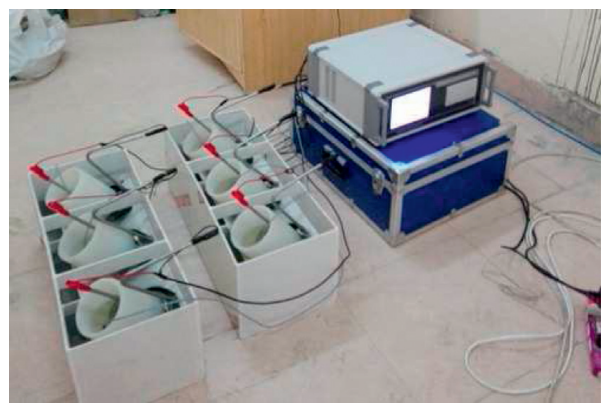

FIgURE 4: Overview of RCP testing.

the mass of specimens was measured after exposure periods of $14,28,56$, and 120 days.

\section{Results and Discussion}

\subsection{Compressive Properties}

3.1.1. Compressive Strength $\left(f_{\mathrm{CM}}\right)$. $f_{\mathrm{CM}}$ of all fifteen mixes at the ages of 28 and 120 days is shown in Figure 5. Both FA and WSF addition showed mixed effects of $f_{\mathrm{CM}}$ depending on their percentage in an HSC mix. The 28 days $f_{\mathrm{CM}}$ of HSC was increased by $6 \%$ at $10 \%$ FA addition. This improvement in $f_{\mathrm{CM}}$ was credited to the effective filling effect and development of pozzolanic products $[12,15]$. While $f_{\mathrm{CM}}$ of HSC decreased notably compared to the reference mix, with the rising level of FA. This could be blamed on a reduction in the overall lime content of the binder. Although smaller particles of FA provided a filling effect, at a high level, FA fails to develop necessary reactions responsible for strength. As FA particles reacted slowly with available portlandite, 


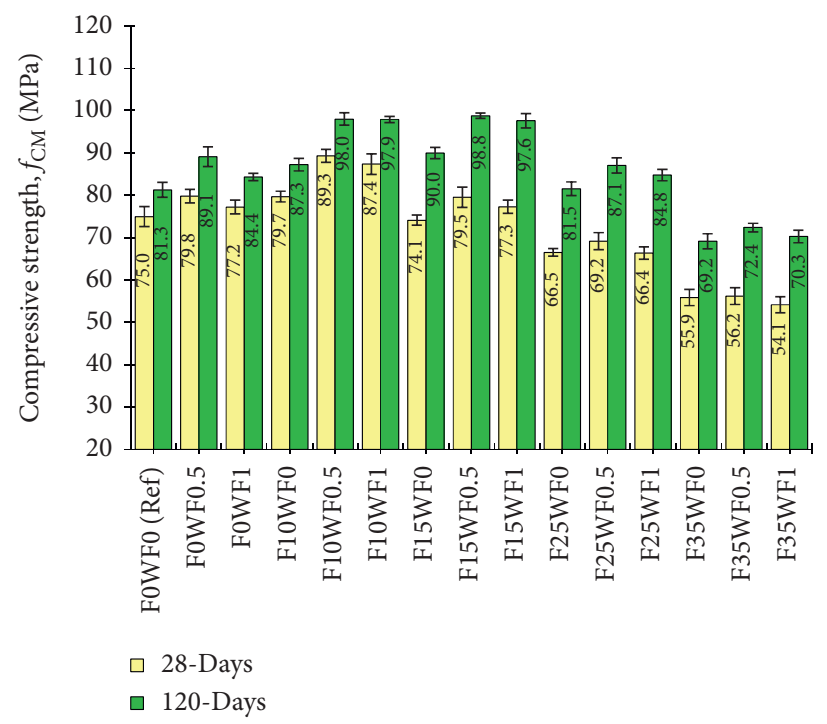

Figure 5: Effect of FA and WSF combinations on compression testing results of concrete.

HSC mixtures containing 10-15\% developed noticeably (i.e., $7-11 \%)$ higher $f_{\mathrm{CM}}$ than the reference mix. While mix containing $25 \%$ FA showed $f_{\mathrm{CM}}$ similar to the reference mix at 120 days.

$0.5 \%$ WSF improved $f_{\mathrm{CM}}$ by about $6.5 \%$ and $10 \%$ at 28 and 120 days, respectively. While $1 \%$ WSF did not show a significant effect on $f_{\mathrm{CM}}$ generally on all five types of plain mixes $(1,4,7,10,13)$. At a high-volume fraction, the negative effect of WSF can be blamed on an increase in porosity and heterogeneity in the HSC matrix. A high volume of fibers produces small void pockets that decrease the efficiency of fibers contributing to the compression stiffness of concrete. Similar behavior was observed with WSF in another study [37]. Moreover, new steel fiber also showed mixed effects on $f_{\mathrm{CM}}$ of HSC with varying doses $[56,57]$. High volume doses of fibers were not effective in increasing the peak-load capacity, but these were beneficial to the postpeak response. The high volume of WSF restricted the sharp failure and helped in sustaining a noticeable residual strength after peak load. The failure patterns of plain HSC and WSF-HSC are shown in Figure 6.

The combined effect of WSF and FA on $f_{\mathrm{CM}}$ of HSC at 28 and 120 days can be observed in Figure 7. Maximum $f_{\mathrm{CM}}$ was shown by HSC containing $0.5 \%$ WSF and $10-15 \%$ FA because both $0.5 \%$ WSF and $10-15 \%$ FA were individually helpful to $f_{\mathrm{CM}}$; therefore, their combined addition significantly improved $f_{\mathrm{CM}}$. Mix no. 5 (F10WF0.5) showed $19 \%$ and $21 \%$ greater $f_{\mathrm{CM}}$ than reference mix at 28 and 120 days, respectively. It is also worth mentioning that, due to the increase in age and hardening of the binder with 10-15\% FA, $1 \%$ WSF showed a similar effect on $f_{\mathrm{CM}}$ compared to $0.5 \%$ WSF at 120 days. An increase in age may improve the bond of fibers with HSC's matrix. Therefore, F10WF1 showed performance similar to FA10WF0.5 at 120 days.

At 120 days, maximum $f_{\mathrm{CM}}$ was shown by FA15WF0.5, which was $22 \%$ higher than that of the reference mix. At 120 days, mixes incorporating $0.5-1 \% \mathrm{WSF}$ and $10-25 \%$ FA showed noticeably higher $f_{\mathrm{CM}}$ than the reference mix. These results showed the usefulness of ecofriendly FA and WSF in improving $f_{\mathrm{CM}}$. The combined addition of FA and WSF not only improves the mechanical and ductility performance of HSC but also can substantially decrease cost and carbon footprint due to a reduction in cement quantity.

3.1.2. Modulus of Elasticity (ECM). $E_{\mathrm{CM}}$ is a measure of compression stiffness of concrete significantly within the elastic limit state of the material. The results of all HSC mixtures with different combinations of FA and WSF are shown in Figure 8. The relationship between WSF, FA, and relative $E_{\mathrm{CM}}$ of HSC is shown in Figure 9.

The addition of $10 \%$ FA showed a small improvement in $E_{\mathrm{CM}}$ of HSC. In contrast, the 28-day $E_{\mathrm{CM}}$ of HSC decreased considerably with the rising FA percentage. While, at 120 days, $E_{\mathrm{CM}}$ of HSC containing $10-15 \%$ FA was comparable with that of the reference HSC. Small percentages of FA can increase the compression stiffness by decreasing the pore size. The filling effect of small FA particles can cause a small increase in the density of concrete that improves the compressive stiffness, while pozzolanic activity also contributes to strength at lower levels of FA $[7,58]$. In contrast, high-volume FA addition decreases the pozzolanic activity and inactive filler content of concrete increases. This slows the strength development and reduces $E_{\mathrm{CM}}$ [59].

Literature has shown insignificant effects of new steel fibers on $E_{\mathrm{CM}}$ [60] because fibers do not activate when the loading is well within the elastic limit of concrete. Therefore, $E_{\mathrm{CM}}$ of HSC entirely depends on the development level of basic ingredients of concrete. The addition of $1 \% \mathrm{WSF}$ proved detrimental to $E_{\mathrm{CM}}$ as it caused a small reduction of $2-5 \%$ in $E_{\mathrm{CM}}$ because, at a high-volume fraction, the density of concrete might decrease due to the poor dispersion of fibers. $1 \%$ new steel fiber addition also showed a negative effect on $E_{\mathrm{CM}}[60]$. Very few studies investigated the axial stress-strain characteristics of WSF-HSC mixes. A study showed a small increase $(1-8 \%)$ in $E_{\mathrm{CM}}$ of ultra-high 


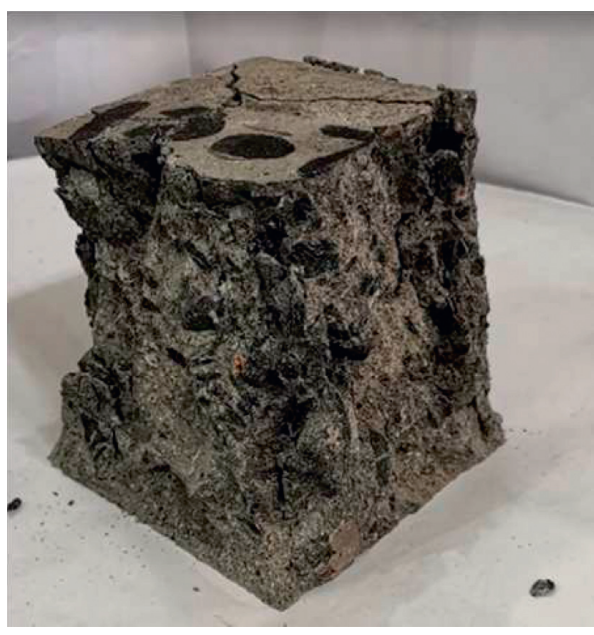

(a)

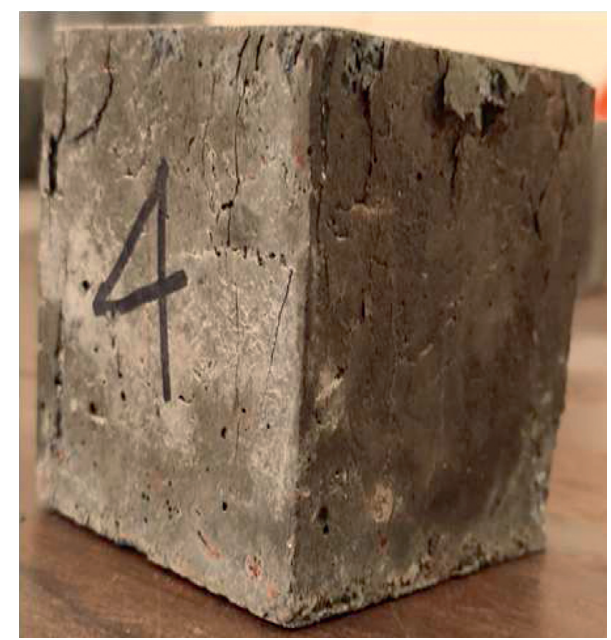

(b)

FIgURE 6: Compression failure. (a) Cube with 0\% WSF. (b) Cube with 1\% WSF.

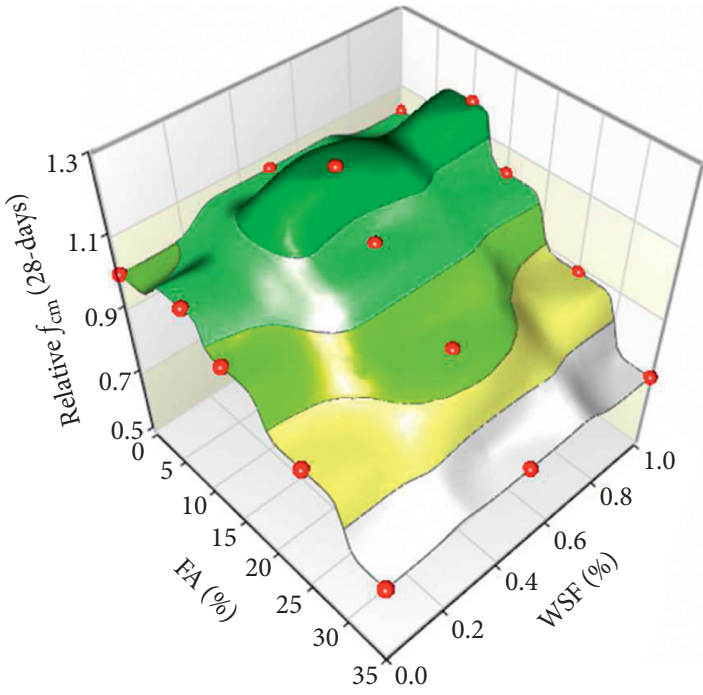

(a)

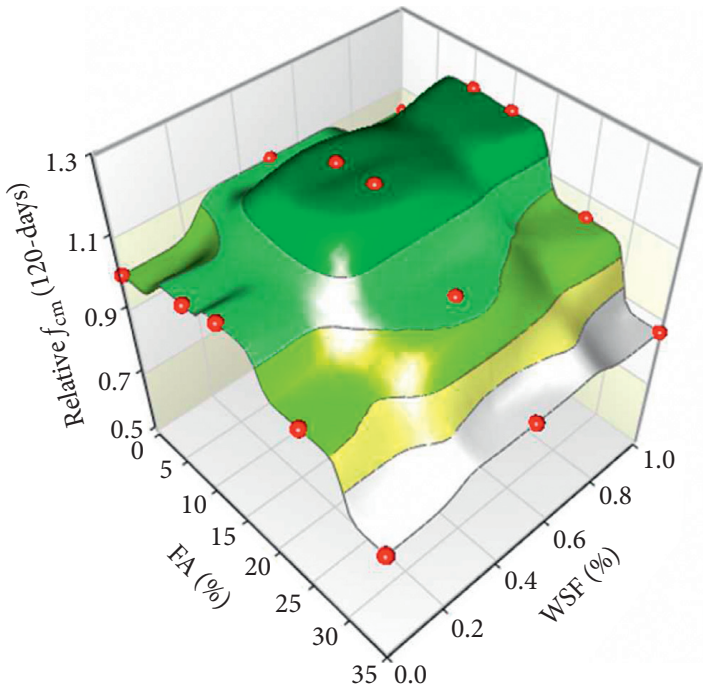

(b)

Figure 7: Relationship between FA, WSF, and relative $f_{\text {CM }}$ values of HSC: (a) 28 days and (b) 120 days.

performance concrete due to $2-3 \%$ volume of WSF [61]. In contrast, a lot of efforts are still required towards understanding the effects of WSF on $E_{\mathrm{CM}}$ of concrete as the deficiency on this topic has been highlighted in a recent review study [62]. However, from this study, it can be concluded that $0.5 \%$ WSF proved to be useful to $E_{\mathrm{CM}}$, while $1 \%$ WSF slightly lowered the $E_{\mathrm{CM}}$.

The maximum $E_{\mathrm{CM}}, 4-5 \%$ higher than reference HSC, was shown by HSC containing $10 \% \mathrm{FA}$ and $0.5 \%$ WSF at both 28 and 120 days. The negative effect of $1 \%$ WSF was more pronounced in HSCs containing a high volume of FA because increasing FA content in the binder decreased the matrix strength and eventually the bond performance of WSF. The low strength of the matrix weakened the grip over fibers; hence, it decreased the efficiency of WSF. In contrast, the negative effect of $1 \% \mathrm{WSF}$ on $E_{\mathrm{CM}}$ was more pronounced at 28 days in the HSC mix with a high volume of FA compared to the $E_{\mathrm{CM}}$ of these mixtures at 120 days. As the age of HSC increased, the negative effect of $1 \%$ WSF on $E_{\mathrm{CM}}$ reduced because the hardening of binder paste improves the bond performance of fibers [41].

\subsection{Tensile Properties}

3.2.1. Splitting-Tensile Strength $\left(f_{\text {CTM }}\right)$. $f_{\text {CTM }}$ was found out by conducting a split-tensile test on standard cylindrical samples of all mixes. The average $f_{\text {CTM }}$ of each HSC mix with standard deviation value is shown in Figure 10. Brittleness is a major issue with the application of HSC because it has a small $f_{\text {CTM }}$ value compared to the respective $f_{\mathrm{CM}}$. Therefore, the fiber addition becomes a viable option to increase the ductility and fire resistance of HSC. As can be seen from the 


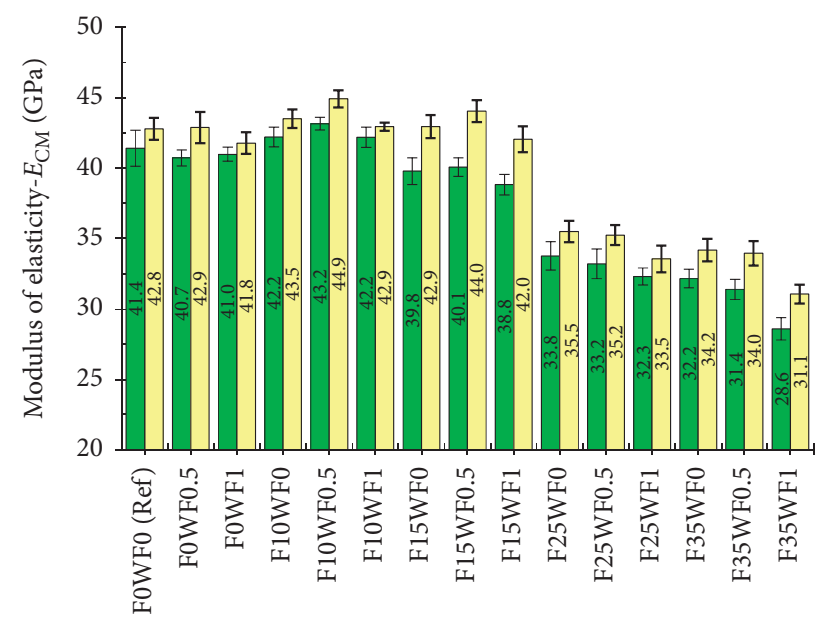

$$
\begin{aligned}
& \text { 28-Days } \\
& \text { 120-Days }
\end{aligned}
$$

Figure 8: Effect of different combinations of WSF and FA on the $(\mathrm{E})_{\mathrm{CM}}$ of HSC.

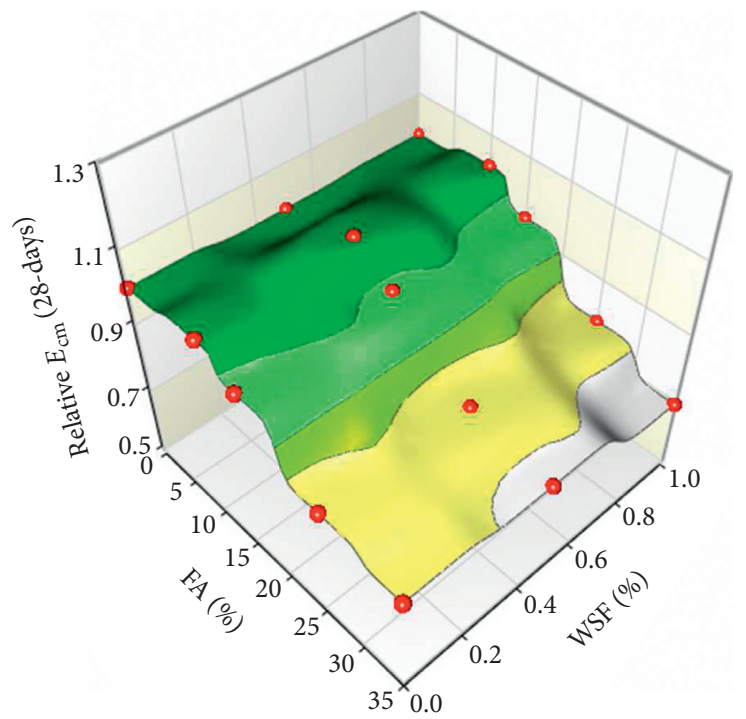

(a)

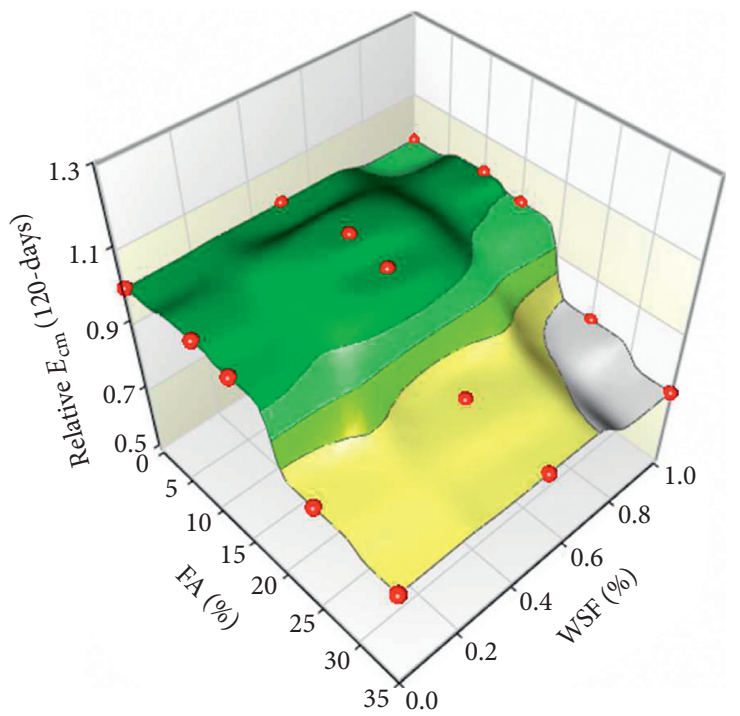

(b)

FIgURE 9: Relationship between FA, WSF, and relative (E) CM values of HSC: (a) 28 days and (b) 120 days.

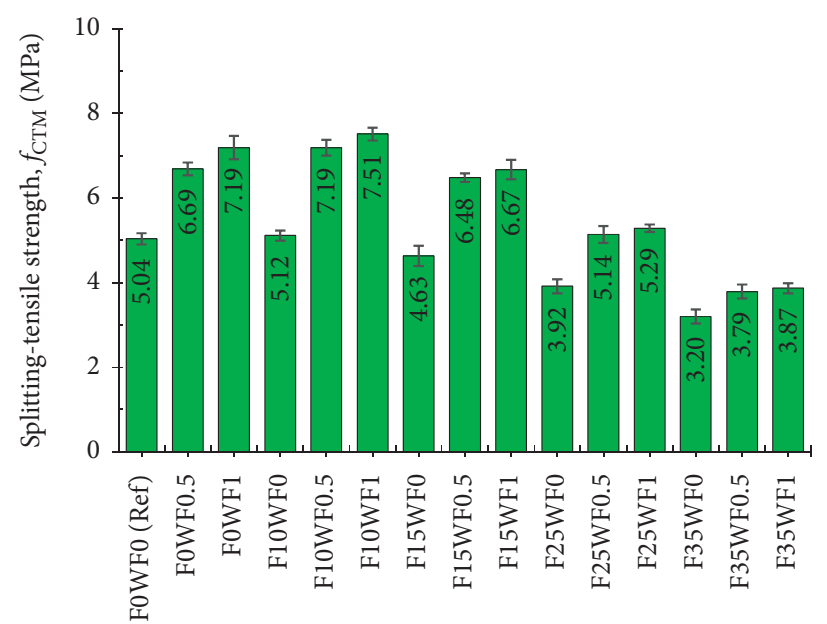

Figure 10: The $f_{\text {СTM }}$ value of HSC with different incorporation levels of FA and WSF. 
results, WSF proved very useful in advancing the tensile strength of HSC. An overall improvement of $32 \%$ and $42 \%$ was noticed in $f_{\text {CTM }}$ of HSC (containing $0 \%$ FA) at $0.5 \%$ and $1 \%$ WSF addition. Studies have shown positive effects of WSF on $f_{\text {CTM }}$ [63]. This improvement, as observed with industrial fibers, is credited to the crack-arresting behavior of WSF [27]. FA addition showed a negative effect on $f_{\text {CTM }}$ of HSC. FA higher than $10 \%$ caused a drastic decline in tensile strength, whereas $10 \%$ replacement of cement with FA caused a small $2 \%$ increase in $f_{\text {CTM }}$. In contrast, 15,25 , and $35 \%$ FA addition reduce $f_{\text {CTM }}$ of HSC by 8,22 , and $36 \%$, respectively, because the decrease in strength development with the rising FA percentage in a binder and the filler effect of FA particles does not contribute to tensile strength.

The combined addition of $1 \% \mathrm{WSF}$ and $10 \%$ FA showed an increase of $49 \%$ in $f_{\text {CTM }}$ of HSC compared to the reference HSC mix. This showed using a smaller percentage of FA as cement replacement can synergize the benefits of using FA and WSF together. There was a certain improvement in the bond strength of WSF with the addition of $10 \%$ FA in the binder matrix. This has been observed with the combined use of FA (at a small level) and industrial steel [9] and glass fibers [58]. FA particles being spherical and smaller than cement particles can improve the particle packing in the binder matrix of HSC, in addition to the pozzolanicity potential of FA. These positive effects of a small percentage of FA reflect the improvement of the bond performance of fibers.

WSF has shown some positive effects on high-volume FA-HSC mixes. As we know, FA is ecofriendly and the cost and carbon footprint of concrete significantly drops when it replaces cement in the binder [7], but it badly affects the tensile performance of HSC. Therefore, WSF can help in controlling the drop of $f_{\text {CTM }}$ due to the addition of a high volume of FA. The more important observation here is that HSC made with $25 \%$ FA and $1 \%$ WSF showed higher $f_{\text {СTM }}$ than the reference HSC mix. The mix made with both FA and WSF was not just better in $f_{\text {CTM }}$ than the reference mix, but it was also ecofriendly and cheap compared to the reference mix. WSF addition was not just useful in increasing the load at which HSC failed under splitting action. It was also very beneficial in containing the crack-width after the peak load, as shown in Figure 11. After the peak load, WSF-reinforced HSC possessed high residual strength than the plain HSC mix.

The net effect of WSF addition on $f_{\text {CTM }}$ of HSC was reduced with the rising FA level in the binder. As FA decreased the strength of HSC, the grip of the binder over WSF weakens. Therefore, the net increase in $f_{\text {СтM }}$ due to WSF addition was significantly influenced by the binder composition.

The ratio between $f_{\text {CTM }}$ and $f_{\mathrm{CM}}$ of each HSC mix is shown in Figure 12. This ratio can be used to assess the ductility of a particular concrete mix. A higher value of the $f_{\mathrm{CTM}} / f_{\mathrm{CM}}$ ratio indicates high ductility, while a lower value shows low ductility. It can be observed that the use of fibers increased the $f_{\mathrm{CTM}} / f_{\mathrm{CM}}$ of HSC. The increase in $f_{\mathrm{CTM}} / f_{\mathrm{CM}}$ of HSC was proportional to the reinforcement index. Figure 12 also showed that $f_{\text {CTM }}$ of HSC increased from $6.7 \%$ to $9.3 \%$ of $f_{\mathrm{CM}}$ as WSF content increased from 0 to $1 \%$. $f_{\mathrm{CTM}} / f_{\mathrm{CM}}$ of FA mixes went on decreasing with the rise in FA content. This showed that the brittleness of concrete increased when a high volume of FA was used. The relationship surface between FA and WSF contents and relative or normalized $f_{\mathrm{CTM}}$ is shown in Figure 13. According to this surface, maximum relative $f_{\text {CTM }}$ of HSC was achieved within $0-15 \%$ FA and $0.5-1 \%$ WSF contents. On the contrary, the lowest relative $f_{\text {CTM }}$ was shown by mixes incorporating $35 \%$ FA for a given content of WSF.

3.2.2. Modulus of Rupture $\left(f_{C R M}\right)$. $f_{\text {CRM }}$ is another indirect measure of the tensile capacity of cement-based composites. The effect of different combinations of FA and WSF on $f_{\mathrm{CRM}}$ of HSC is shown in Figure 14. The variation in $f_{\text {CRM }}$ results with the changing FA and WSF contents was similar to that observed in the case of $f_{\text {CTM }}$ results. However, $f_{\text {CRM }}$ was highly sensitive to WSF addition compared to $f_{\mathrm{CTM}}$. Comparing the results of $f_{\mathrm{CM}}, E_{\mathrm{CM}}, f_{\mathrm{CTM}}$, and $f_{\mathrm{CRM}}$ revealed that WSF addition yielded maximum benefits to $f_{\mathrm{CRM}}$. Similar to WSF, other industrial fibers (steel, coconut, glass, polypropylene, etc.) $[43,56,58,64]$ have also shown maximum utilization in flexural behavior.

$f_{\text {CRM }}$ of HSC increased by $56 \%$ and $78 \%$ due to the addition of $0.5 \%$ and $1 \%$ WSF, respectively. This showed a significant increment in the flexural toughness and ductility of HSC with WSF addition. On the contrary, a significant reduction in $f_{\mathrm{CRM}}$ was noticed at $15-35 \%$ FA addition. $f_{\mathrm{CRM}}$ of HSC dropped by $37 \%$ at $35 \%$ replacement of cement with FA. At high volume incorporation, FA is generally known to aggravate the mechanical properties of HSC similarly $[5,13,65]$. The common effect of FA addition was observed on the reduction level of all tested mechanical strength properties, that is, $f_{\mathrm{CM}}, E_{\mathrm{CM}}, f_{\mathrm{CTM}}$, and $f_{\mathrm{CRM}}$. It is because the change in microstructural growth is similarly reflected in compression and tensile properties.

The combination of $10 \% \mathrm{FA}$ and $0.5-1 \%$ WSF showed superior results among all mixes. F10WF1 and F10WF0.5 showed $83 \%$ and $65 \%$ higher rupture strength than the reference mix. The synergistic effect of FA and WSF was noticed in F10WF1 and F10WF0.5. For example, the net increase in $f_{\text {CRM }}$ due to $1 \%$ WSF addition in $0 \%$ FA-HSC was $70 \%$, while $1 \%$ WSF showed an improvement of about $80 \%$ in $10 \%$ FA-HSC. The high net effect of WSF was achieved because of the synergistic behavior of 10\% FA and 1\% WSF. Improvement in the particle size distribution within HSC's matrix increases the pullout strength of WSF. However, the efficiency of WSF decreased significantly in HSC mixes containing a high volume of FA because the binder matrix containing high FA volume showed slow development and incomplete growth of microstructure at an early age.

It is generally known that FA incorporation shows some detrimental effects on the tensile properties of concrete. However, it is an ecofriendly and durable substitution of cement. The results of this study show that mixes with up to $25 \%$ FA can show better $f_{\mathrm{CRM}}$ than reference mix if $0.5-1 \%$ WSF is used as the reinforcement. Although choosing industrial fibers, to overcome the $f_{\mathrm{CRM}}$ strength loss of HSC 


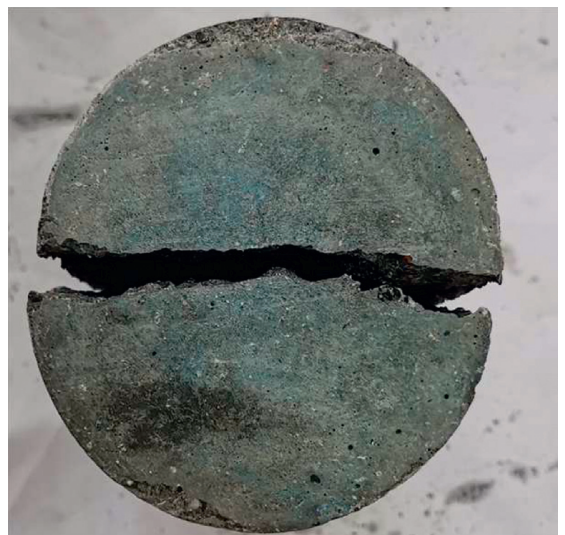

(a)

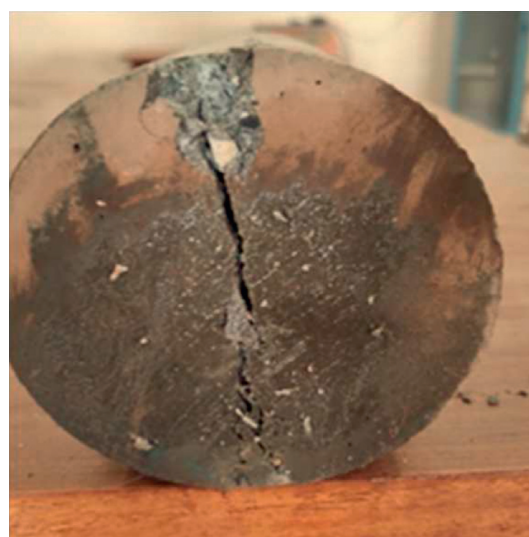

(b)

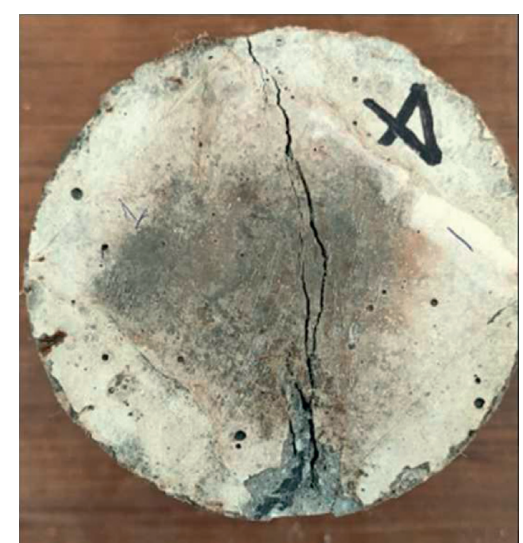

(c)

FIGURE 11: Splitting-tensile failure modes of HSC with (a) 0\% WSF, (b) $0.5 \%$ WSF, and (c) $1 \%$ WSF.

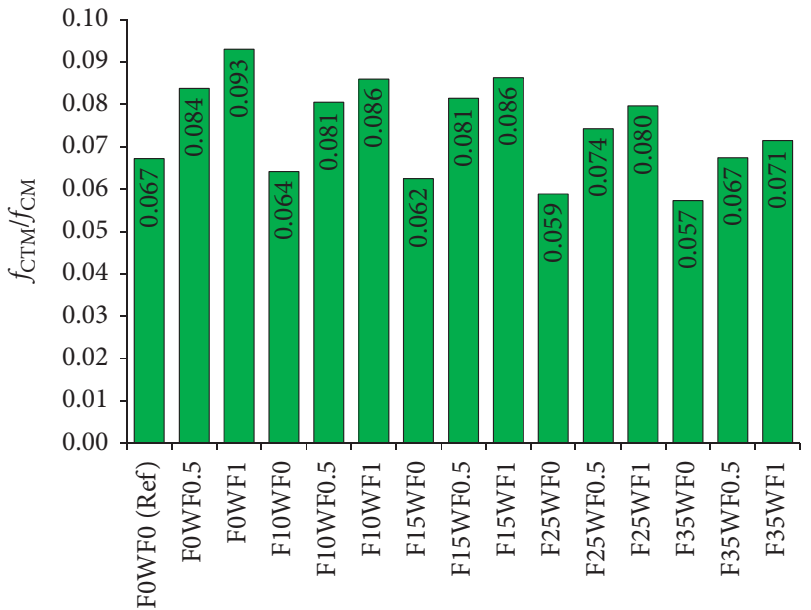

FIGURE 12: The ratio between $f_{\mathrm{CTM}}$ and $f_{\mathrm{CM}}$ of all HSC mixes.

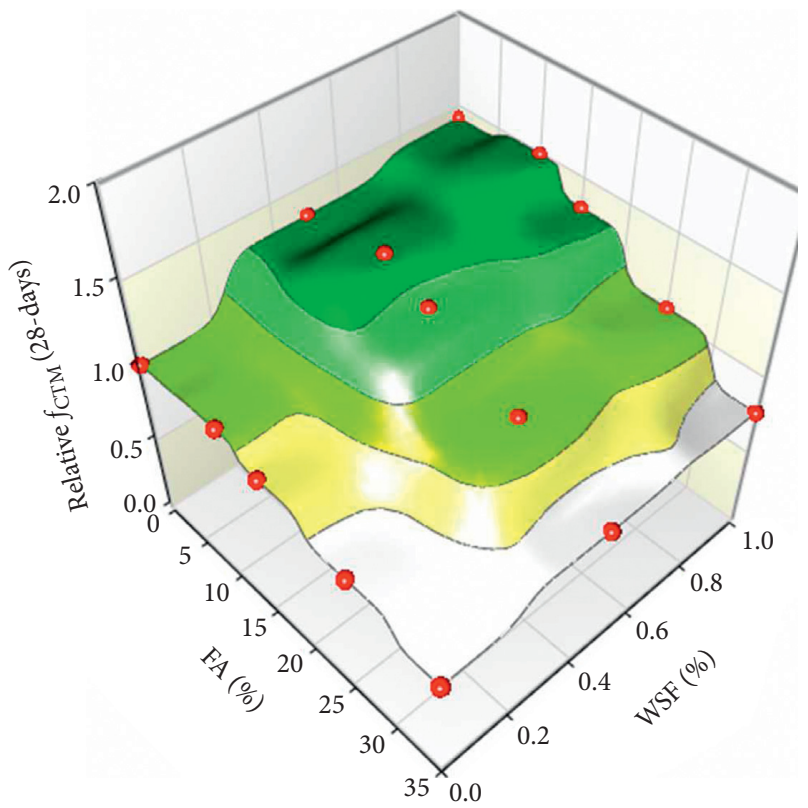

FIGURE 13: Relationship between WSF and FA contents and relative $f_{\text {CTM. }}$

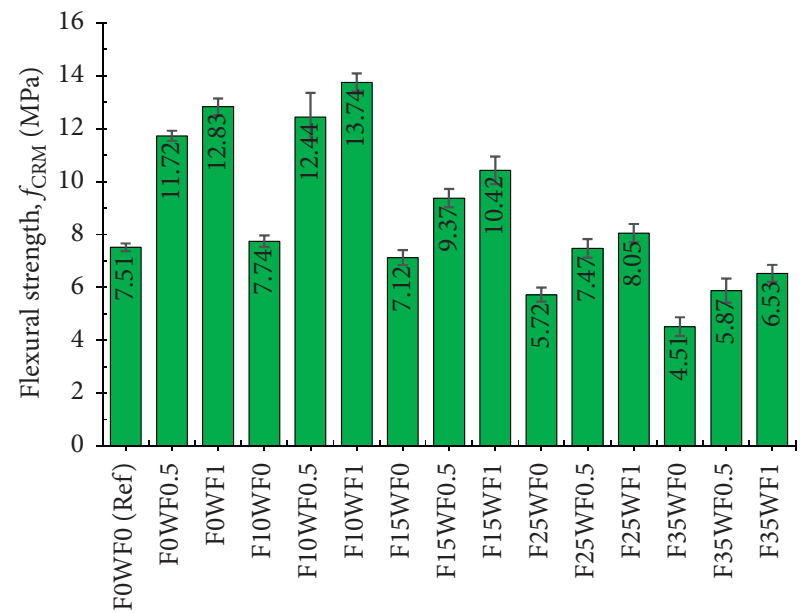

FIGURE 14: The $f_{\text {CRM }}$ of each HSC mix with different incorporation levels of FA and WSF.

due to FA, is an expensive and non-ecofriendly option, WSF, which is a waste product with minimum energy involved in its processing, can be used with FA to produce ductile and ecofriendly HSC. In addition to economic benefits, the HSC composite built with FA and WSF offers high flexural toughness and residual strength than reference HSC.

The $f_{\mathrm{CRM}} / f_{\mathrm{CM}}$ ratio of each HSC mix is shown in Figure 15. It is noticed that plain HSC mixes made with or without FA showed $f_{\mathrm{CRM}} / f_{\mathrm{CM}}$ ratio between 0.06 and 0.1 . It means for HSC, $f_{\text {CRM }}$ is about $6-10 \%$ of the corresponding $f_{\mathrm{CM}}$. Fiber-reinforced HSC mixes yielded $f_{\mathrm{CRM}}$ about $16-18 \%$ of the $f_{\mathrm{CM}}$ value. High $f_{\mathrm{CRM}} / f_{\mathrm{CM}}$ was shown by HSCs made with $0.5-1 \%$ WSF and $0-10 \%$ FA. The use of high-volume FA decreased the $f_{\mathrm{CRM}} / f_{\mathrm{CM}}$ value significantly even for WSFreinforced mixes. F35WF0, F35F0.5, and F35F1 showed $f_{\mathrm{CRM}} / f_{\mathrm{CM}}$ values notably lower than the plain-reference mix (FOWF0). These findings suggested that the strength and development of the binder matrix substantially influence the efficiency of WSF. A 3-dimensional plot between relative $f_{\text {CRM }}$, WSF, and FA percentage is shown in Figure 16. The highest plateau (the maximum values of relative $f_{\mathrm{CRM}}$ ) on this surface belongs to $0.5-1 \%$ WSF contents and 10\% FA, 


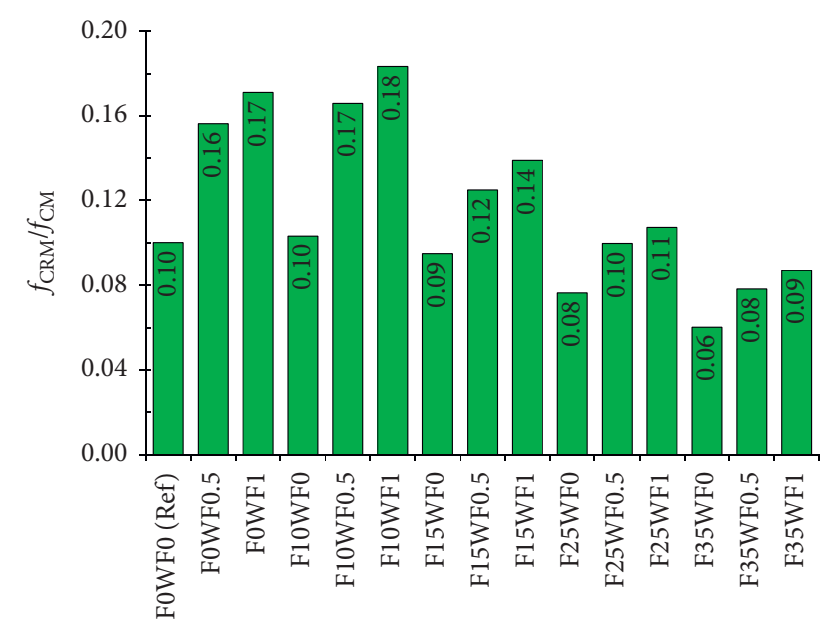

Figure 15: The ratio between $f_{\mathrm{CRM}}$ and $f_{\mathrm{CM}}$ of all HSC mixes.

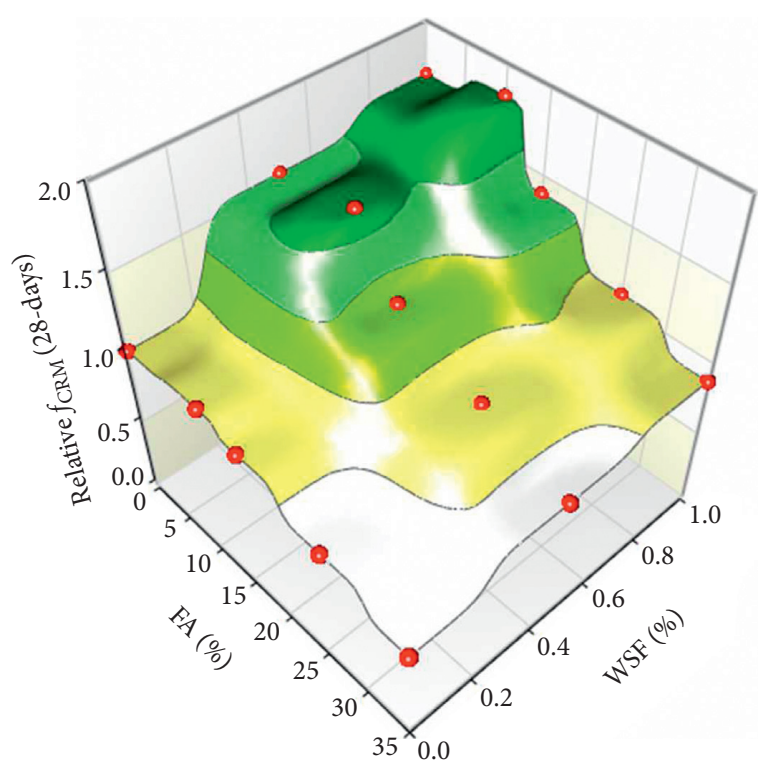

FIgURE 16: Relationship between WSF and FA contents and relative $f_{\text {CRM. }}$

while the lowest valley on the surface (the minimum values of relative $f_{\text {CRM }}$ ) is related to HSC mixes with $25-35 \%$ FA and $0-0.5 \%$ WSF contents.

\subsection{Chloride Permeability Test Results}

3.3.1. Rapid Chloride Permeability (RCP). RCP test is used for rapid assessment of chloride-ion permeability resistance of cementitious concretes. The representative $R C P$ value of a mix largely depends on the microstructural density and development. Moreover, it is also affected by the ability of concrete to conduct electrical charges. The effect of WSF and FA was determined on $R C P$ resistance of HSC at 28 and 120 days. The results are presented in Figure 17.

The RCP values of all HSC mixes are lower than 2000 coulombs, which means $R C P$ of all mixes comes under the category of "low" chloride-ion permeability, according to

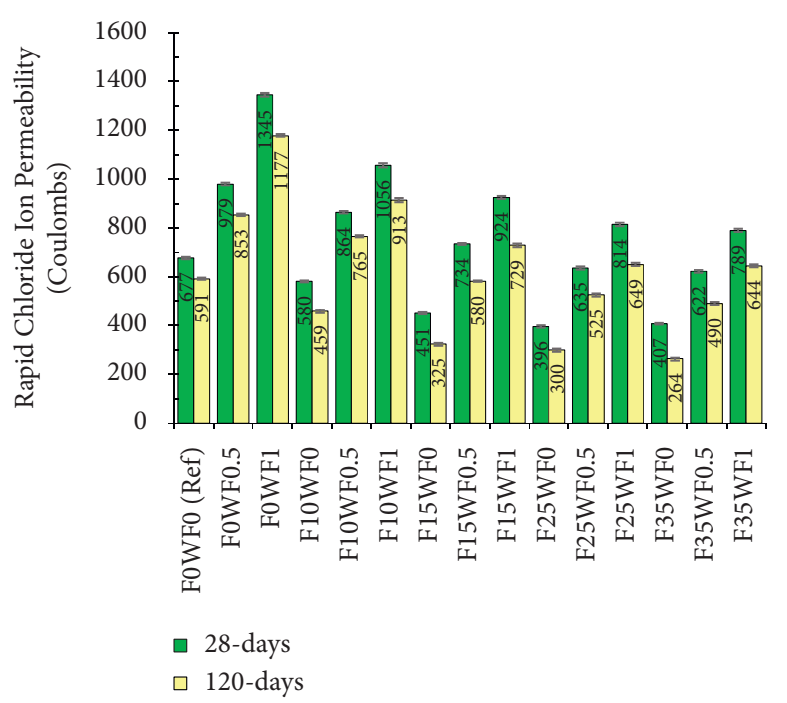

FIGURE 17: RCP of each HSC mix with different incorporation levels of FA and WSF.

Table 4. Moreover, plain mixes made with and without FA showed $R C P$ values significantly lower than those noticed for WSF-reinforced mixes. RCP values of plain HSC mixes are lower than 1000, which indicates that plain mixes have "very low" chloride-ion permeability.

Very low $R C P$ values of plain mixes are mainly because of a small water-binder ratio (i.e., 0.3). $R C P$ of concrete further decreased with the rise in FA content; see Figure 18. The use of $10,15,25$, and 35 FA decreased the $R C P$ by $15 \%$, $34 \%, 42 \%$, and $40 \%$, respectively. The decrease in RCP with FA inclusion in the binder is mainly credited to the filling effect of FA particles. Moreover, an increase in the tricalcium aluminate content of concrete increases the chloride binding capacity of concrete [10]. The inverse relationship between FA and $R C P$ has also been observed in past research [67]. A decrease in the electrical conductivity of concrete has also been reported with the addition of slag in the binder of HSC [43].

The high electrical conductivity of WSF increased the RCP of HSC. About $50 \%$ and $100 \%$ increase of RCP was observed at the addition of 0.5 and $1 \%$ volume fraction of WSF in HSC. This immense increase in RCP indicates that WSF-HSC is more vulnerable to corrosion attacks. Not only are the main steel bars vulnerable to corrosion attack but also the filaments of WSF can degrade over time in HSC. Degradation of both WSF and main reinforcement will eventually lead to a decrease in the capacity of structural elements. The small increase in the permeability of HSC due to fiber addition may also contribute to an increase in $R C P$ since permeability also favors the rapid penetration of chloride ions. A significant increase in the electrical conductivity of HSC has been observed due to the incorporation of industrial steel fiber [57]. The directly-proportional relationship between RCP and WSF contents is shown in Figure 19.

The use of FA significantly decreased the RCP of WSFreinforced HSC. This means that FA can be used to compensate for the loss in chloride durability of HSC due to WSF 
TABLE 4: Electrical indication of chloride durability [66].

\begin{tabular}{lc}
\hline Electrical charge (coulombs) & Chloride penetrability of concrete \\
\hline$>4000$ & Very high \\
$2000-4000$ & Normal \\
$1000-2000$ & Low \\
$100-1000$ & Very low \\
$<100$ & Insignificant \\
\hline
\end{tabular}

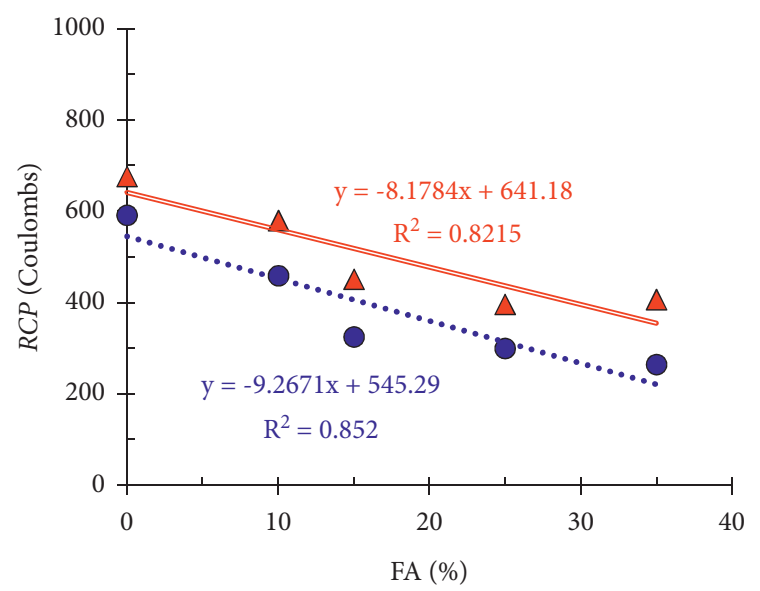

$\triangle$ RCP (28-Days)

- RCP (120-Days)

FIGURE 18: Relationship between FA content in binder and corresponding $R C P$ values of HSC.

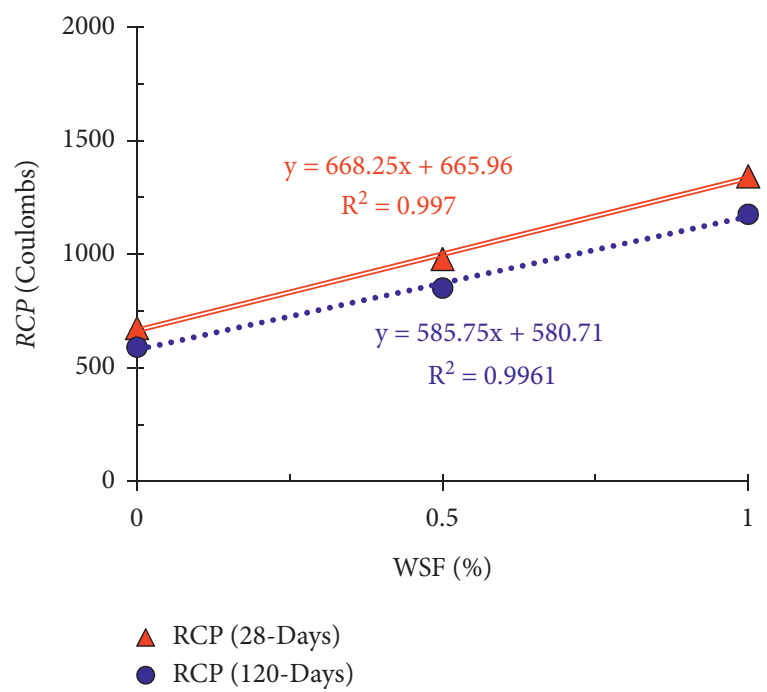

FIGURE 19: Relationship between WSF content and corresponding $R C P$ values of HSC.

addition. To obtain RCP values of WSF-reinforced HSC in the range of the "very low" category, the use of $10-15 \%$ FA is necessary. The use of the high volume of FA showed high $R C P$ resistance, but it reduced the strength, which would probably be the main drawback considering the application of high-volume FA in HSC. However, it is not possible to achieve an $R C P$ value similar to the reference mix when using 1\% WSF without considering the use of the high volume of FA.

3.3.2. Chloride Penetration Depth (CPD). The CPD is a reliable and more realistic measurement of chloride penetrability of cementitious material than $R C P$, which is not affected by the electrical conductivity of the material. It largely depends on the porosity, saturation of pore-solution, and microstructural growth of concrete. The CPD of each HSC mix after immersion in chloride solution for 28 and 120 days is shown in Figure 20.

The incorporation of FA leads to a drop in $C P D$, indicating that chloride durability of concrete increases with FA addition. As already explained in Section 3.3.1, FA improves the distribution of particle sizes in the matrix of HSC. The decrease in pore size slows the movement of the chloridebearing medium into the concrete. Moreover, alumina silicate particles of FA have chloride binding capacity. The minimum $C P D$ was shown by HSC containing $25 \% \mathrm{FA}$. The relationship between FA (\%) and CPD of HSC is shown in Figure 21. The CPD value of HSC kept decreasing until $25 \%$ FA, while a small increase in $C P D$ was observed at $35 \% \mathrm{FA}$. This can be explained by a decline in the microstructural growth of the binder matrix at a high volume of FA addition. However, still, all FA mixes showed notably lower $C P D$ values than the reference mix.

Contrary to $R C P$ test results, $C P D$ test results show a small effect of WSF on the chloride permeability of concrete; see Figure 22 because the high conductivity of WSF-reinforced concrete does not affect the penetration of chloride ions in natural conditions. CPD was increased only by $2-7 \%$ at $0.5-1 \%$ addition of WSF. The small increase in porosity due to WSF addition is responsible for a slight rise in the $C P D$. A study has shown that chloride diffusion of concrete is not significantly affected by the electrical conductivity of the material [68]. Therefore, steel fiber addition did not increase the chloride diffusion in the concrete. HSC mixes made with the combined FA and WSF addition show CPD values significantly lower than the reference mix. A small increase in CPD caused by WSF is substantially suppressed by FA addition.

3.3.3. Relationship between CPD and RCP. The relationship between $C P D$ and $R C P$ values of all HSC mixes is shown in Figure 23. Since $R C P$ is significantly influenced by electrical conductivity, it does not find a strong correlation with $C P D$, as $C P D$ is not affected by the conductivity of the material. For plain mixes (made with or without FA), it is possible to find a strong correlation between $C P D$ and $R C P$ values, but for WSF-reinforced mixes, it is difficult to correlate these two parameters without considering the effect of fiber.

Figure 24 shows the relationship between $C P D, R C P$, and WSF content of HSC at each level of FA. The relationship is derived in the format of equation (1), where $C P D$ is calculated as a function of RCP and volume of WSF ( $\left.V_{\mathrm{WSF}}\right)$. A and $\mathrm{B}$ are constants of the linear equation. $R C P$ is taken as an independent variable because it is determined quickly compared to $C P D$. Therefore, $C P D$ can be estimated from 


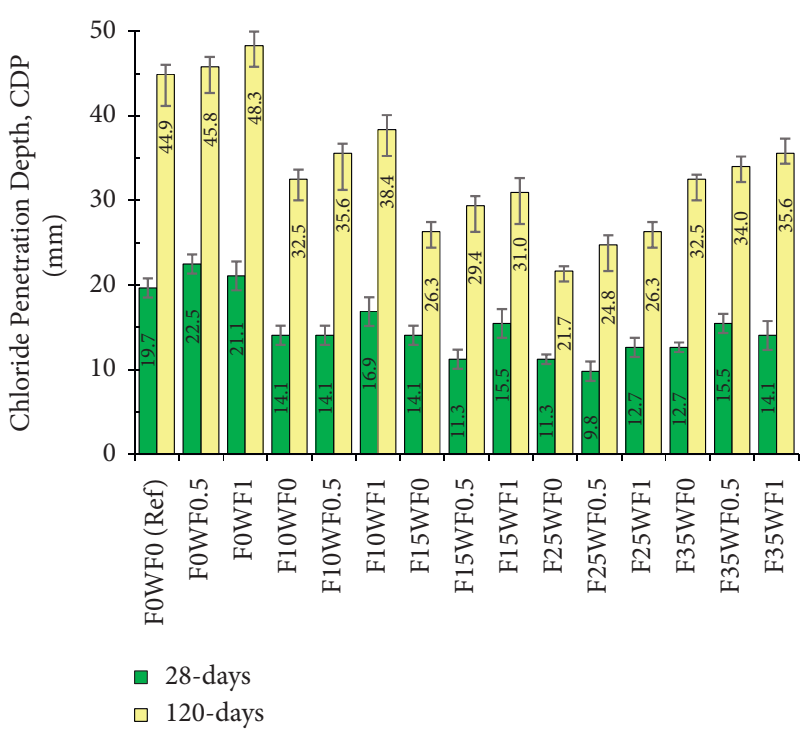

Figure 20: $C P D$ of each HSC mix with different incorporation levels of FA and WSF.

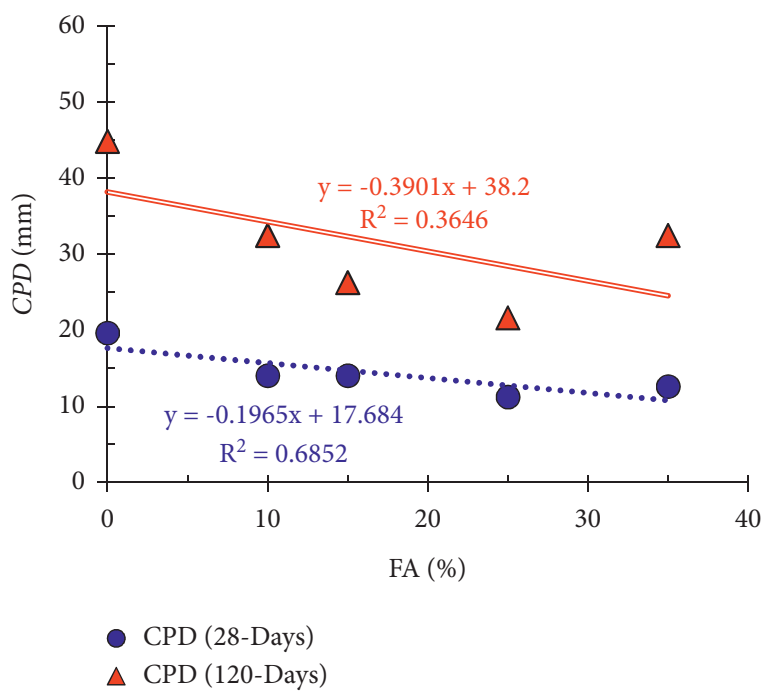

Figure 21: Relationship between FA content in the binder and corresponding $C P D$ values of HSC.

$R C P$ for WSF-reinforced concretes. As shown in Figure 24, $C P D$ and $R C P$ can be correlated strongly if $V_{\mathrm{WSF}}$ is considered. These relationships have important implications for applications of steel fiber-reinforced concretes, as CPD values, which are found after a long time, can be accurately estimated from $R C P$ as a function of $V_{\mathrm{WSF}}$ :

$$
C P D=R C P \times\left(A \times V_{\mathrm{WSF}}+B\right) .
$$

3.4. Sulfuric Acid Attack Resistance (AAR). Cementitious concretes often experience acidic environments in their application. In most cases, acidic solution dissolves both hydrated and unhydrated cementitious compounds, leading to the deterioration of the mechanical performance of

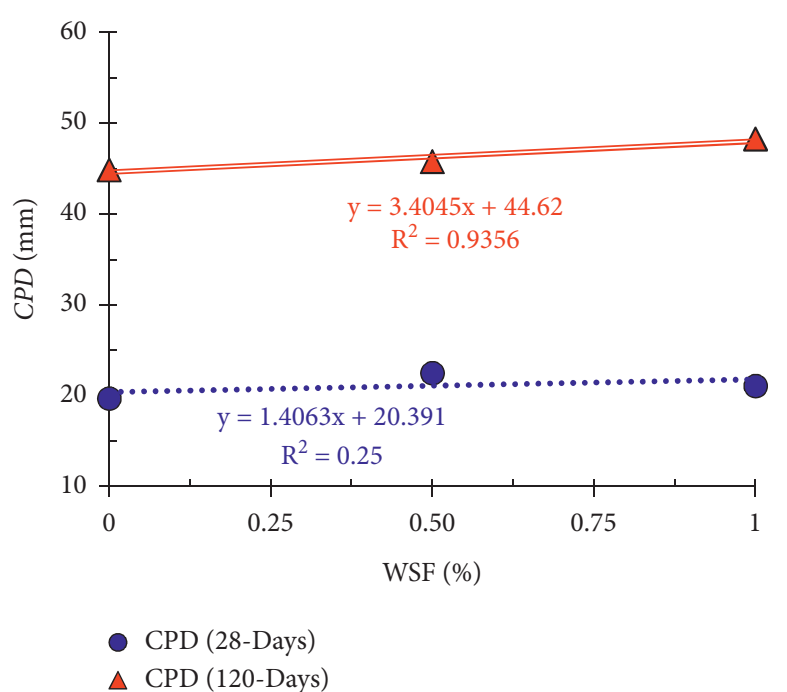

FIGURE 22: Relationship between WSF content and corresponding $C P D$ values of HSC.

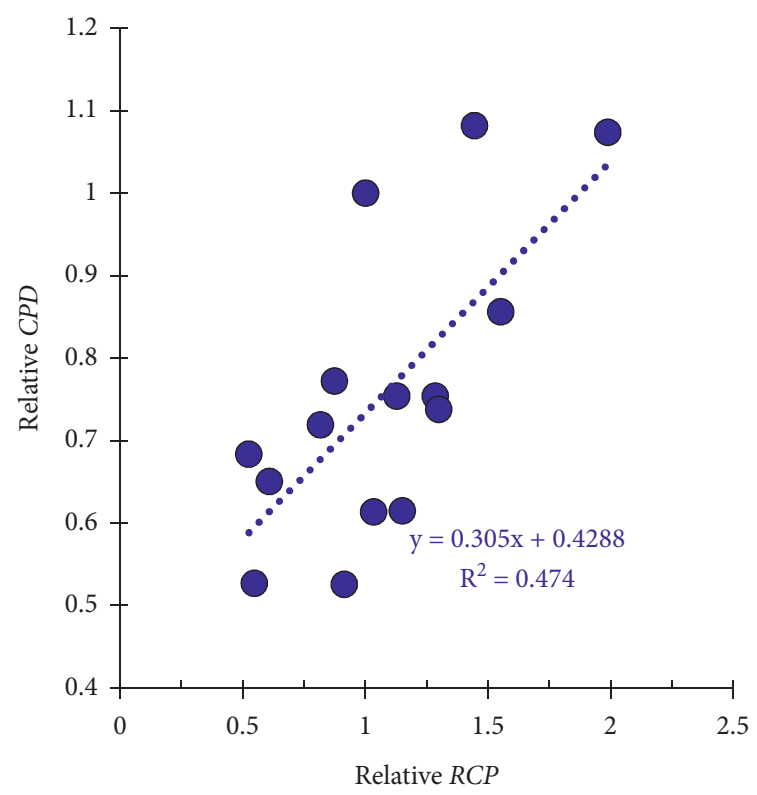

- RCP vs CDP

Linear (RCP vs CDP)

Figure 23: Relationship between $C P D$ and $R C P$.

concrete. If calcareous aggregates are used, they are also dissolved by acidic action. Therefore, the measurement of $A A R$ becomes a related durability parameter. In this study, the durability of HSC mixes was measured in an artificial acidic medium created by a $5 \%$ solution of sulfuric acid in tap water. The results of all HSC mixtures are shown in Figure 25.

The plain HSC or reference mix showed the maximum loss in mass compared to all other HSC mixtures at both ages of testing. The $A A R$ of HSC substantially increased due to the addition of both FA and WSF. As FA content increased in 


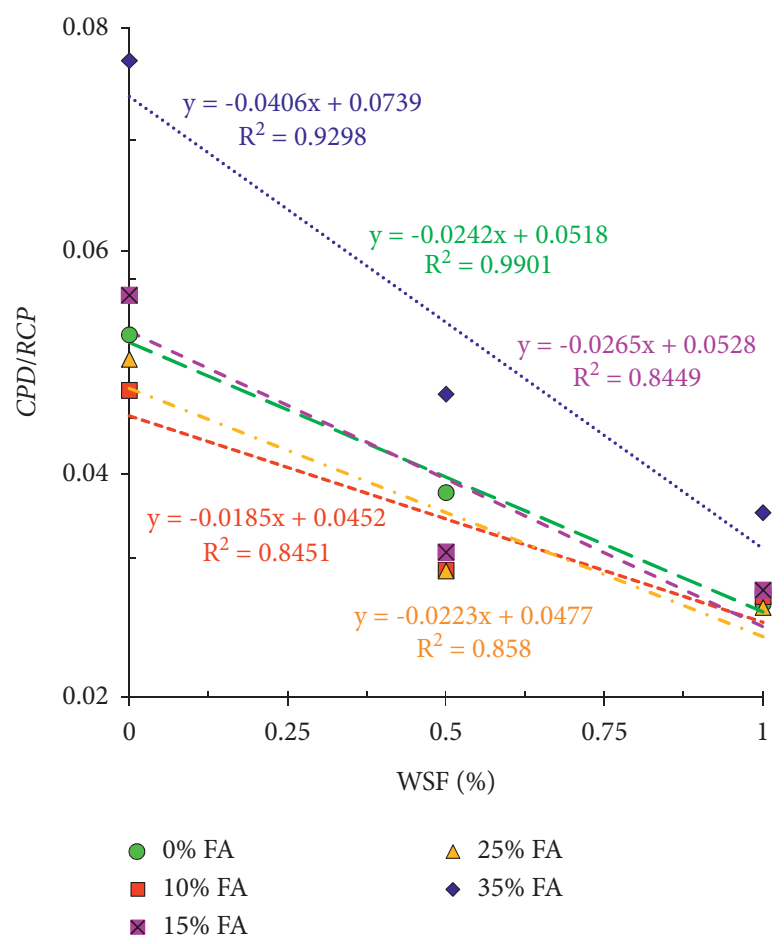

FIGURE 24: Relationship between CPD, RCP, and WSF content of WSF for each level of FA.

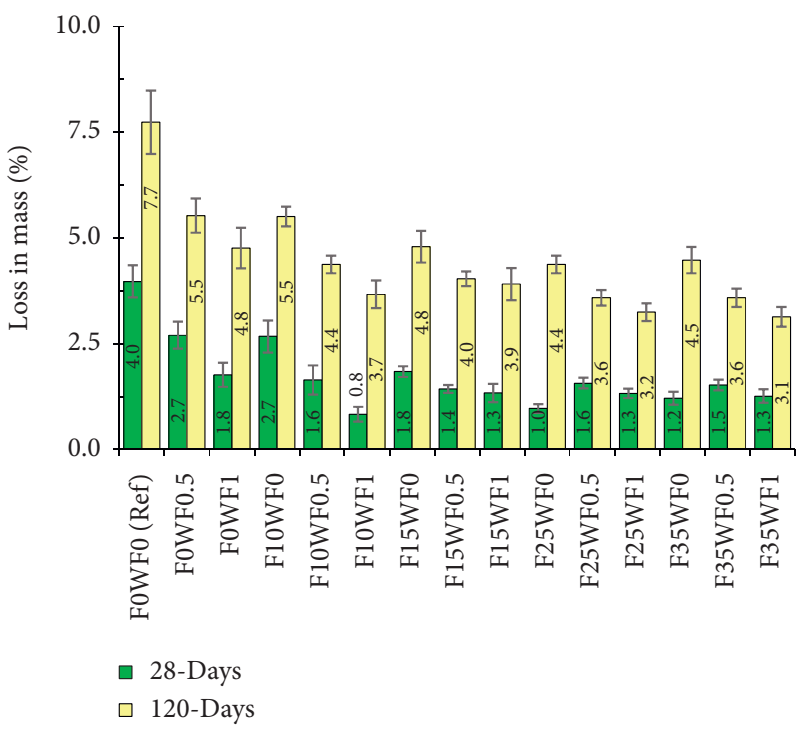

FIGURE 25: Loss in mass of each HSC mix with different incorporation levels of FA and WSF as a result of acid attack.

the concrete, the total alumina-silica content of the binder increased. The rise in FA causes a reduction in the calcium oxide content of the binder. The reduction in calcium hydrates and unhydrates makes the HSC resistant to acid attack. Similar observations were observed due to the addition of rice husk ash into the binder [68]. The increase in silica content and decline in lime content is the major reason responsible for the high durability of HSC in the acid attack. Another reason is that the low permeability of FA mixtures slows the movement of acidic solution into the matrix of the concrete.
The relationship between FA, WSF contents, and relative loss in mass (LIM) under acid attack are shown in Figure 26. This relationship shows that high $A A R$ or low LIM under acid attack is achieved with high-level incorporation of WSF and FA. WSF increases $A A R$ by its capability to hold crack propagation. Sulfate attack is accompanied by the formation of expansive salts and water. It exerts the pressure inside the binder matrix to disintegrate the microstructure of concrete and finally deteriorate the mechanical strength of HSC. WSF controls such disintegration and degradation of mechanical strength; as a result, low LIM was observed in mixes with fibers. 


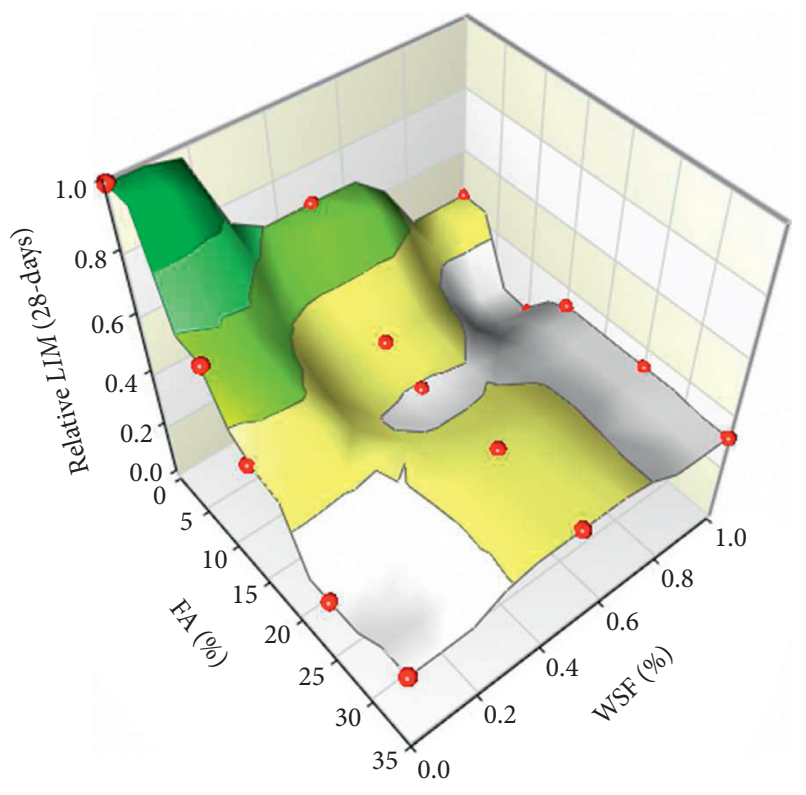

(a)

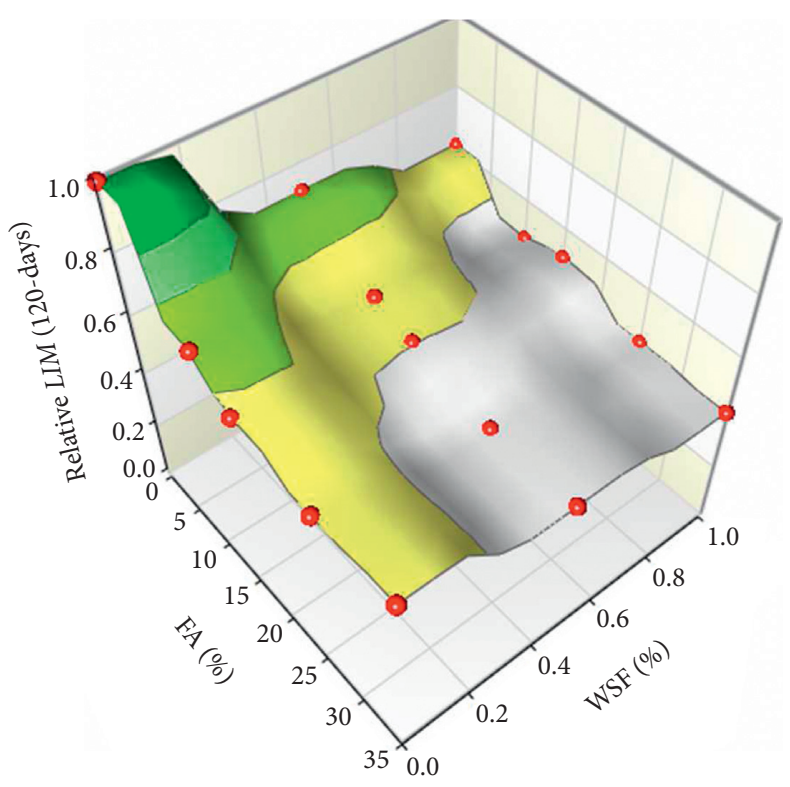

(b)

FIgURE 26: Relationship between FA, WSF, and relative loss in mass-LIM values of HSC: (a) 28 days and (b) 120 days.

Improvement in the AAR of concretes with industrial steel and glass fibers has been reported in previous studies due to their crack-bridging effects $[9,58,69]$. Mixes made with $10-35 \%$ FA and $0.5-1 \%$ WSF showed almost half disintegration under acid attack compared to the reference mixture. WSF also improved the residual strength of HSC exposed to an acidic solution.

\section{Conclusions}

In the present study, the combined effect of fly ash (FA) and waste tire steel fiber (WSF) was investigated on the durability and mechanical performance of high-strength concrete (HSC). The main theme of this research is the advancement in knowledge about ecofriendly and ductile cementitious composites. The following are the key findings of the present research:

(1) HSC made with low-to-medium levels of FA $(10-15 \%)$ and WSF $(0.5 \%)$ showed optimum $f_{\mathrm{CM}}$. High-level incorporation of FA lessened the efficacy of WSF on $f_{\mathrm{CM}}$. For all incorporation levels of $\mathrm{FA}$, the optimum dosage of WSF is $1 \%$. $E_{\mathrm{CM}}$ of HSC did not change considerably due to WSF. Lessening in $E_{\mathrm{CM}}$ was observed with the rising FA and WSF contents in HSC. HSC made with $0.5 \%$ WSF and $10 \%$ FA showed higher $E_{\mathrm{CM}}$ than the reference mix.

(2) $f_{\text {СтM }}$ of HSC was considerably sensitive to WSF addition. The HSC made with $10 \%$ FA and $1 \%$ WSF showed maximum $f_{\text {СтM }}$, about $50 \%$ higher than the reference HSC mix. The splitting-tensile efficiency of WSF decreased with the rising FA percentage in the binder. Similar to $f_{\text {CTM }}, f_{\text {CRM }}$ was also sensitive to WSF addition. Maximum $f_{\text {CRM }}$ was shown by HSC incorporating $10 \% \mathrm{FA}$ and $1 \% \mathrm{WSF}$, which was $83 \%$ higher than the reference mix.
(3) The RCP of HSC was increased drastically with WSF addition. 1\% WSF addition caused about a $100 \%$ increase in the RCP of HSC mainly because of the high electrical conductivity. FA caused a decrease in $R C P$ with each rising level. FA minimized the negative effect of WSF on RCP. However, RCP should not be taken as a good measure of chloride permeability capacity of steel fiber-reinforced concretes. On the contrary, $C P D$ test results gave realistic values of chloride permeability capability of WSF-reinforced concretes.

(4) The $C P D$ results are not affected by the electrical conductivity. Therefore, WSF addition did not show a drastic increase in $C P D$. All WSF-reinforced mixes incorporating FA showed lower $C P D$ than the reference HSC mix. HSC made with $25 \% \mathrm{FA}$ and $0.5 \%$ WSF showed 50\% lower CPD than the reference mix. A strong mathematical correlation between $C P D$ and $R C P$ can be derived if the volume of WSF is considered.

(5) Both FA and WSF were extremely useful in AAR. Increased integrity of concrete due to the fibers and decline in calcium content of the binder is accountable for excellent acid attack durability of HSC incorporating FA and WSF.

\section{Data Availability}

Data will be provided upon request.

\section{Conflicts of Interest}

The authors declare that they have no conflicts of interest. 


\section{Acknowledgments}

The authors would like to extend their appreciation to the Deanship of Scientific Research at King Khalid University, Saudi Arabia, for funding this work through the Research Group Program under Grant no. RGP. 1/14/42.

\section{References}

[1] D.-Y. Oh, T. Noguchi, R. Kitagaki, and W.-J. Park, "CO2 emission reduction by reuse of building material waste in the Japanese cement industry," Renewable and Sustainable Energy Reviews, vol. 38, pp. 796-810, 2014.

[2] E. Benhelal, G. Zahedi, E. Shamsaei, and A. Bahadori, "Global strategies and potentials to curb $\mathrm{CO} 2$ emissions in cement industry," Journal of Cleaner Production, vol. 51, pp. 142-161, 2013.

[3] N. Mahasenan, S. Smith, and K. Humphreys, "The cement industry and global climate changecurrent and potential future cement industry $\mathrm{CO}_{2}$ emissions," in Proceedings of the Greenhouse Gas Control Technologies-6th International Conference, pp. 995-1000, Elsevier, Pergamon, Turkey, 2003.

[4] M. A. Nisbet, M. G. VanGeem, J. Gajda, and M. Marceau, "Environmental life cycle inventory of portland cement concrete," PCA R\&D Serial, vol. 28, 2000.

[5] R. Kurda, J. de Brito, and J. Silvestre, "Combined economic and mechanical performance optimization of recycled aggregate concrete with high volume of fly ash," Applied Sciences, vol. 8, no. 7, p. 1189, 2018.

[6] M. A. Nawaz, L. A. Qureshi, B. Ali, and A. Raza, "Mechanical, durability and economic performance of concrete incorporating fly ash and recycled aggregates," SN Applied Sciences, vol. 2, no. 2, p. 162, 2020.

[7] R. Kurad, J. D. Silvestre, J. de Brito, and H. Ahmed, "Effect of incorporation of high volume of recycled concrete aggregates and fly ash on the strength and global warming potential of concrete," Journal of Cleaner Production, vol. 166, pp. 485502, 2017.

[8] Astm-C618, Standard Specification for Coal Fly Ash and Raw or Calcined Natural Pozzolan for Use in ConcreteASTM International, West Conshohocken, PA, 2017, http://www.astm. org.

[9] B. Ali, S. S. Raza, R. Kurda, and R. Alyousef, "Synergistic effects of fly ash and hooked steel fibers on strength and durability properties of high strength recycled aggregate concrete," Resources, Conservation and Recycling, vol. 168, Article ID 105444, 2021.

[10] R. Kurda, J. D. Silvestre, J. de Brito, and H. Ahmed, "Optimizing recycled concrete containing high volume of fly ash in terms of the embodied energy and chloride ion resistance," Journal of Cleaner Production, vol. 194, pp. 735-750, 2018.

[11] R. Kurda, J. de Brito, and J. D. Silvestre, "Combined influence of recycled concrete aggregates and high contents of fly ash on concrete properties," Construction and Building Materials, vol. 157, pp. 554-572, 2017.

[12] A. R. Boğa and I. B. Topçu, "Influence of fly ash on corrosion resistance and chloride ion permeability of concrete," Construction and Building Materials, vol. 31, pp. 258-264, 2012.

[13] Y. Hefni, Y. A. E. Zaher, and M. A. Wahab, "Influence of activation of fly ash on the mechanical properties of concrete," Construction and Building Materials, vol. 172, pp. 728-734, 2018.

[14] B. B. Das and S. P. Pandey, "Influence of fineness of fly ash on the carbonation and electrical conductivity of concrete,"
Journal of Materials in Civil Engineering, vol. 23, no. 9, pp. 1365-1368, 2011.

[15] P. Chindaprasirt, C. Chotithanorm, H. T. Cao, and V. Sirivivatnanon, "Influence of fly ash fineness on the chloride penetration of concrete," Construction and Building Materials, vol. 21, no. 2, pp. 356-361, 2007.

[16] D. F. Velandia, C. J. Lynsdale, J. L. Provis, F. Ramirez, and A. C. Gomez, "Evaluation of activated high volume fly ash systems using $\mathrm{Na} 2 \mathrm{SO} 4$, lime and quicklime in mortars with high loss on ignition fly ashes," Construction and Building Materials, vol. 128, pp. 248-255, 2016.

[17] S. H. Gebler and P. Klieger, "Effect of fly ash on physical properties of concrete," Special Publication, vol. 91, pp. 1-50, 1986.

[18] H. Rolander, Potential Applications for High-Strength Concrete in Cast In-Situ Structures, Aalto University, Espoo, Finland, 2019.

[19] M. F. M. Zain, H. B. Mahmud, A. Ilham, and M. Faizal, "Prediction of splitting tensile strength of high-performance concrete," Cement and Concrete Research, vol. 32, no. 8, pp. 1251-1258, 2002.

[20] E. Lubloy, "How does concrete strength affect the fire resistance?" Journal of Structural Fire Engineering, vol. 11, no. 3, 2020.

[21] V. Afroughsabet, L. Biolzi, and P. J. M. Monteiro, “The effect of steel and polypropylene fibers on the chloride diffusivity and drying shrinkage of high-strength concrete," Composites Part B: Engineering, vol. 139, pp. 84-96, 2018.

[22] S. Teng, V. Afroughsabet, and C. P. Ostertag, "Flexural behavior and durability properties of high performance hybridfiber-reinforced concrete," Construction and Building Materials, vol. 182, pp. 504-515, 2018.

[23] A. B. Kizilkanat, N. Kabay, V. Akyüncü, S. Chowdhury, and A. H. Akça, "Mechanical properties and fracture behavior of basalt and glass fiber reinforced concrete: an experimental study," Construction and Building Materials, vol. 100, pp. 218-224, 2015.

[24] A. Akbar and K. M. Liew, "Multicriteria performance evaluation of fiber-reinforced cement composites: an environmental perspective," Composites Part B: Engineering, vol. 218, Article ID 108937, 2021.

[25] A. Al-Tikrite and M. N. S. Hadi, "Mechanical properties of reactive powder concrete containing industrial and waste steel fibres at different ratios under compression," Construction and Building Materials, vol. 154, pp. 1024-1034, 2017.

[26] M. A. Aiello, F. Leuzzi, G. Centonze, and A. Maffezzoli, "Use of steel fibres recovered from waste tyres as reinforcement in concrete: pull-out behaviour, compressive and flexural strength," Waste Management, vol. 29, no. 6, pp. 1960-1970, 2009.

[27] M. Mastali and A. Dalvand, "Use of silica fume and recycled steel fibers in self-compacting concrete (SCC)," Construction and Building Materials, vol. 125, pp. 196-209, 2016.

[28] K. M. Liew and A. Akbar, "The recent progress of recycled steel fiber reinforced concrete," Construction and Building Materials, vol. 232, Article ID 117232, 2020.

[29] G. Centonze, M. Leone, and M. A. Aiello, "Steel fibers from waste tires as reinforcement in concrete: a mechanical characterization," Construction and Building Materials, vol. 36, pp. 46-57, 2012.

[30] C. C. Santos and J. P. C. Rodrigues, "Compressive strength at high temperatures of a concrete made with recycled tire textile and steel fibers," in Proceedings of the MATEC Web of Conferences, p. 7004, October 2013. 
[31] M. Leone, G. Centonze, D. Colonna, F. Micelli, and M. A. Aiello, "Fiber-reinforced concrete with low content of recycled steel fiber: shear behaviour," Construction and Building Materials, vol. 161, pp. 141-155, 2018.

[32] K. Aghaee, M. A. Yazdi, and K. D. Tsavdaridis, "Investigation into the mechanical properties of structural lightweight concrete reinforced with waste steel wires," Magazine of Concrete Research, vol. 67, no. 4, pp. 197-205, 2015.

[33] O. Sengul, "Mechanical properties of slurry infiltrated fiber concrete produced with waste steel fibers," Construction and Building Materials, vol. 186, pp. 1082-1091, 2018.

[34] G. F. Peng, X. J. Niu, and Q. Q. Long, "Experimental study of strengthening and toughening for recycled steel fiber reinforced ultra-high performance concrete," Key Engineering Materials, Trans Tech Publ, vol. 629-630, pp. 104-111, 2015.

[35] A. H. Farhan, A. R. Dawson, and N. H. Thom, "Damage propagation rate and mechanical properties of recycled steel fiber-reinforced and cement-bound granular materials used in pavement structure," Construction and Building Materials, vol. 172, pp. 112-124, 2018.

[36] Y. Wang, H. C. Wu, and V. C. Li, "Concrete reinforcement with recycled fibers," Journal of Materials in Civil Engineering, vol. 12, no. 4, pp. 314-319, 2000.

[37] M. Ahmadi, S. Farzin, A. Hassani, and M. Motamedi, "Mechanical properties of the concrete containing recycled fibers and aggregates," Construction and Building Materials, vol. 144, pp. 392-398, 2017.

[38] M. Nili and V. Afroughsabet, "Combined effect of silica fume and steel fibers on the impact resistance and mechanical properties of concrete," International Journal of Impact Engineering, vol. 37, no. 8, pp. 879-886, 2010.

[39] J.-K. Kim, J.-S. Kim, G. J. Ha, and Y. Y. Kim, “Tensile and fiber dispersion performance of ECC (engineered cementitious composites) produced with ground granulated blast furnace slag," Cement and Concrete Research, vol. 37, no. 7, pp. 1096-1105, 2007.

[40] Y. Ling, K. Wang, W. Li, G. Shi, and P. Lu, "Effect of slag on the mechanical properties and bond strength of fly ash-based engineered geopolymer composites," Composites Part B: Engineering, vol. 164, pp. 747-757, 2019.

[41] Z. Wu, C. Shi, and K. H. Khayat, "Influence of silica fume content on microstructure development and bond to steel fiber in ultra-high strength cement-based materials (UHSC)," Cement and Concrete Composites, vol. 71, pp. 97-109, 2016.

[42] I. B. Topçu and M. Canbaz, "Effect of different fibers on the mechanical properties of concrete containing fly ash," Construction and Building Materials, vol. 21, no. 7, pp. 1486-1491, 2007.

[43] V. Afroughsabet, L. Biolzi, and T. Ozbakkaloglu, "Influence of double hooked-end steel fibers and slag on mechanical and durability properties of high performance recycled aggregate concrete," Composite Structures, vol. 181, pp. 273-284, 2017.

[44] C. D. Atiş and O. Karahan, "Properties of steel fiber reinforced fly ash concrete," Construction and Building Materials, vol. 23, pp. 392-399, 2009.

[45] O. Karahan and C. D. Atiş, "The durability properties of polypropylene fiber reinforced fly ash concrete," Materials \& Design, vol. 32, no. 2, pp. 1044-1049, 2011.

[46] S. S. Raza, L. A. Qureshi, and B. Ali, "Residual mechanical strength of glass fiber reinforced reactive powder concrete exposed to elevated temperatures," SN Applied Sciences, vol. 2, no. 9, 2020.

[47] E. Nazarimofrad, F. U. A. Shaikh, and M. Nili, "Effects of steel fibre and silica fume on impact behaviour of recycled aggregate concrete," Journal of Sustainable Cement-Based Materials, vol. 6, no. 1, pp. 54-68, 2017.

[48] M. Papachristoforou, E. K. Anastasiou, and I. Papayianni, "Durability of steel fiber reinforced concrete with coarse steel slag aggregates including performance at elevated temperatures," Construction and Building Materials, vol. 262, Article ID 120569, 2020.

[49] Astm-C150, Standard Specification for Portland Cement, ASTM International, West Conshohocken, PA, USA, 2018.

[50] Astm-C33, Standard Specification for Concrete AggregatesASTM International, West Conshohocken, PA, USA, 2018.

[51] Astm-C39, Standard Test Method for Compressive Strength of Cylindrical Concrete Specimens, ASTM International, West Conshohocken, PA, USA, 2015, http://www.astm.org.

[52] Astm-C469, Standard Test Method for Static Modulus of Elasticity and Poisson's Ratio of Concrete in Compression, ASTM International, West Conshohocken, PA, USA, 2014, http://www.astm.org.

[53] Astm-C496, Standard Test Method for Splitting Tensile Strength of Cylindrical Concrete SpecimensASTM International, West Conshohocken, PA, 2017, http://www.astm.org.

[54] Astm-C1609, Standard Test Method for Flexural Performance of Fiber-Reinforced Concrete (Using Beam with Third-Point Loading), ASTM International, West Conshohocken, PA, 2019, http://www.astm.org.

[55] Astm-C1202, Standard Test Method for Electrical Indication of Concrete's Ability to Resist Chloride Ion PenetrationASTM International, West Conshohocken, PA, 2017, http://www. astm.org.

[56] B. Ali, R. Kurda, B. Herki et al., "Effect of varying steel fiber content on strength and permeability characteristics of high strength concrete with micro silica," Materials, vol. 13, no. 24, p. $5739,2020$.

[57] V. Afroughsabet and T. Ozbakkaloglu, "Mechanical and durability properties of high-strength concrete containing steel and polypropylene fibers," Construction and Building Materials, vol. 94, pp. 73-82, 2015.

[58] B. Ali, L. A. Qureshi, S. H. A. Shah, S. U. Rehman, I. Hussain, and M. Iqbal, "A step towards durable, ductile and sustainable concrete: simultaneous incorporation of recycled aggregates, glass fiber and fly ash," Construction and Building Materials, vol. 251, Article ID 118980, 2020.

[59] A. F. Hashmi, M. Shariq, and A. Baqi, "An investigation into age-dependent strength, elastic modulus and deflection of low calcium fly ash concrete for sustainable construction," Construction and Building Materials, vol. 283, Article ID 122772, 2021.

[60] J. Xie, L. Huang, Y. Guo et al., "Experimental study on the compressive and flexural behaviour of recycled aggregate concrete modified with silica fume and fibres," Construction and Building Materials, vol. 178, pp. 612-623, 2018.

[61] M. N. Isa, K. Pilakoutas, M. Guadagnini, and H. Angelakopoulos, "Mechanical performance of affordable and eco-efficient ultra-high performance concrete (UHPC) containing recycled tyre steel fibres," Construction and Building Materials, vol. 255, Article ID 119272, 2020.

[62] H. U. Ahmed, R. H. Faraj, N. Hilal, A. A. Mohammed, and A. F. H. Sherwani, "Use of recycled fibers in concrete composites: a systematic comprehensive review," Composites Part B: Engineering, vol. 215, Article ID 108769, 2021.

[63] O. Onuaguluchi and N. Banthia, "Scrap tire steel fiber as a substitute for commercial steel fiber in cement mortar: engineering properties and cost-benefit analyses," Resources, Conservation and Recycling, vol. 134, pp. 248-256, 2018. 
[64] M. Khan and M. Ali, "Improvement in concrete behavior with fly ash, silica-fume and coconut fibres," Construction and Building Materials, vol. 203, pp. 174-187, 2019.

[65] N. Bouzoubaâ, M. H. Zhang, and V. M. Malhotra, "Mechanical properties and durability of concrete made with high-volume fly ash blended cements using a coarse fly ash," Cement and Concrete Research, vol. 31, no. 10, pp. 1393-1402, 2001.

[66] D. B. McDonald, "The rapid chloride permeability test and its correlation to the 90-day chloride ponding test," PCI Journal, vol. 39, no. 1, pp. 38-47, 1994.

[67] O. A. Mohamed and W. Al Hawat, "Influence of fly ash and basalt fibers on strength and chloride penetration resistance of self-consolidating concrete," Materials Science Forum, vol. 866, pp. 3-8, 2016.

[68] M. Koushkbaghi, M. J. Kazemi, H. Mosavi, and E. Mohseni, "Acid resistance and durability properties of steel fiberreinforced concrete incorporating rice husk ash and recycled aggregate," Construction and Building Materials, vol. 202, pp. 266-275, 2019.

[69] V. Marcos-Meson, G. Fischer, C. Edvardsen, T. L. Skovhus, and A. Michel, "Durability of steel fibre reinforced concrete (SFRC) exposed to acid attack - a literature review," Construction and Building Materials, vol. 200, pp. 490-501, 2019. 